\title{
Sodium Channels Contribute to Degeneration of Dorsal Root Ganglion Neurites Induced by Mitochondrial Dysfunction in an In Vitro Model of Axonal Injury
}

\author{
Anna-Karin Persson, ${ }^{1,2}$ Insil Kim, ${ }^{1,2}$ Peng Zhao, ${ }^{1,2}$ Mark Estacion, ${ }^{1,2}$ Joel A. Black, ${ }^{1,2}$ and Stephen G. Waxman ${ }^{1,2}$ \\ ${ }^{1}$ Department of Neurology and Center for Neuroscience and Regeneration Research, Yale University School of Medicine, New Haven, Connecticut 06510; \\ and ${ }^{2}$ Rehabilitation Research Center, VA Connecticut Healthcare System, West Haven, Connecticut 06516
}

Axonal degeneration occurs in multiple neurodegenerative disorders of the central and peripheral nervous system. Although the underlying molecular pathways leading to axonal degeneration are incompletely understood, accumulating evidence suggests contributions of impaired mitochondrial function, disrupted axonal transport, and/or dysfunctional intracellular $\mathrm{Ca}^{2+}$-homeostasis in the injurious cascade associated with axonal degeneration. Utilizing an in vitro model of axonal degeneration, we studied a subset of mouse peripheral sensory neurons in which neurites were exposed selectively to conditions associated with the pathogenesis of axonal neuropathies in vivo. Rotenone-induced mitochondrial dysfunction resulted in neurite degeneration accompanied by reduced ATP levels and increased ROS levels in neurites. Blockade of voltage-gated sodium channels with TTX and reverse ( $\mathrm{Ca}^{2+}$-importing) mode of the sodium-calcium exchanger (NCX) with KB-R7943 partially protected rotenone-treated neurites from degeneration, suggesting a contribution of sodium channels and reverse NCX activity to the degeneration of neurites resulting from impaired mitochondrial function. Pharmacological inhibition of the $\mathrm{Na}^{+} / \mathrm{K}^{+}$-ATPase with ouabain induced neurite degeneration, which was attenuated by TTX and KB-R7943, supporting a contribution of sodium channels in axonal degenerative pathways accompanying impaired $\mathrm{Na}^{+} / \mathrm{K}^{+}$-ATPase activity. Conversely, oxidant stress $\left(\mathrm{H}_{2} \mathrm{O}_{2}\right)$-induced neurite degeneration was not attenuated by TTX. Our results demonstrate that both energetic and oxidative stress targeted selectively to neurites induces neurite degeneration and that blockade of sodium channels and of reverse NCX activity blockade partially protects neurites from injury due to energetic stress, but not from oxidative stress induced by $\mathrm{H}_{2} \mathrm{O}_{2}$.

\section{Introduction}

Axonal degeneration is associated with multiple neurological conditions, including central disorders such as multiple sclerosis, Alzheimer's disease, and Parkinson's disease (Waxman, 2006; Kiryu-Seo et al., 2010; Campbell et al., 2012; Lingor et al., 2012) and peripheral neuropathies such as small fiber neuropathy (SFN) and Charcot-Marie-Tooth disease (Lacomis, 2002; Bednarik et al., 2009; Pareyson and Marchesi, 2009). Although the molecular mechanisms that underlie axonal degeneration are incompletely understood, contributions of mitochondrial dysfunction, disruption of axonal transport, and/or dysregulation of $\left[\mathrm{Ca}^{2+}\right]_{\mathrm{i}}$ have been implicated in the injurious cascade leading to the degeneration of axons in numerous neurodegenerative disor-

\footnotetext{
Received May 20, 2013; revised 0ct. 22, 2013; accepted 0ct. 31, 2013.

Author contributions: A.-K.P., M.E., J.A.B., and S.G.W. designed research; A.-K.P., I.K., P.Z., and J.A.B. performed research; A.-K.P., I.K., M.E., and J.A.B. analyzed data; A.-K.P., J.A.B., and S.G.W. wrote the paper.

This work was supported by the Rehabilitation Research Service and Medical Research Service, Department of Veterans Affairs (grant to S.G.W.). The Center for Neuroscience and Regeneration Research is a collaboration of the Paralyzed Veterans of America with Yale University. A.-K.P. was in part supported by a fellowship from the Swedish Research Council (K2010-78PK-21636-01-2). We thank P. Shah and P.Zwinger for excellent technical assistance and Sulayman D. Dib-Hajj, PhD, for helpful discussions.

The authors declare no competing financial interests.

Correspondence should be addressed to Stephen G. Waxman, MD, PhD, Neuroscience and Regeneration Research Center, VA Connecticut Healthcare System, 950 Campbell Avenue, Bldg. 34, West Haven, CT 06516. E-mail: stephen.waxman@yale.edu.

DOI:10.1523/JNEUROSCI.2148-13.2013

Copyright $\odot 2013$ the authors $\quad 0270-6474 / 13 / 3319250-12 \$ 15.00 / 0$
}

ders (Delettre et al., 2000; Zuchner et al., 2004; Dutta et al., 2006; Court and Coleman, 2012; Millecamps and Julien, 2013). Impaired mitochondrial function has been proposed to contribute to axonal damage through multiple pathways, including ROS production and energetic stress due to impaired ATP production and altered $\mathrm{Ca}^{2+}$ homeostasis (Court and Coleman, 2012; Park et al., 2013). Disruption of axonal transport has also been linked to the pathogenesis of axon degeneration through diverse mechanisms, including impairment of mitochondrial health and translocation of molecular constituents (Chen and Chan, 2009; Sheng and Cai, 2012).

Early work by Stys et al. (1992) provided evidence that sodium channel activity contributes to axonal dysfunction in an in vitro model of energetic stress. In this and subsequent studies, axonal dysfunction was linked to reduced $\mathrm{Na}^{+} / \mathrm{K}^{+}$ATPase capacity, leading to increased $\left[\mathrm{Na}^{+}\right]_{\mathrm{i}}$ and reversal of the sodium-calcium exchanger (NCX) to operate in $\mathrm{Ca}^{2+}$-importing mode (Stys et al., 1992; Lehning et al., 1996; Li et al., 2000). Accumulating evidence supports the hypothesis of a contribution of sodium channel activity in pathways leading to axonal degeneration. For example, sodium channel blockers provide protection of axons in in vivo models of neuroinflammatory disorders (Bechtold et al., 2005; Morsali et al., 2013), spinal cord injury (Hains et al., 2004; Kaptanoglu et al., 2005), and glaucoma (Hains and Waxman, 2005). Additional support for a contribution of sodium channels in axonal degenerative pathways is provided by recent studies 
that identified gain-of-function mutations in sodium channels in patients with idiopathic SFN, which is accompanied by a reduced density of intraepidermal nerve fibers (Faber et al., 2012a; Faber et al., 2012b).

Here, we determined the contribution of sodium channels and reverse sodium-calcium exchange to neurite degeneration in two in vitro models of axonal degeneration: induced mitochondrial dysfunction and microtubule disruption. Our results demonstrate that both impaired mitochondrial function and microtubule disruption targeted selectively to neurites induce neurite degeneration. We also show that blockade of sodium channels with TTX and of reverse sodium-calcium exchange with KB-R7943 partially protects neurites from injury resulting from impaired mitochondrial function but not microtubule injury. We further demonstrate that reduced $\mathrm{Na}^{+} / \mathrm{K}^{+}$ATPase capacity can induce neurite degeneration that is partially rescued by blockade of sodium channels and reverse NCX activity, whereas oxidant $\left(\mathrm{H}_{2} \mathrm{O}_{2}\right)$-induced neurite degeneration is not protected by blockade of sodium channels.

\section{Materials and Methods}

Animal experiments were approved by the Institutional Animal Care and Use Committee at the VA Connecticut Healthcare System and conducted in accordance with the National Institutes of Health Guide for the Care and Use of Laboratory Animals and the recommendations of the International Association for the Study of Pain.

Animals. Transgenic mice (of either sex) expressing Cre recombinase under control of the Nav1.8 promotor were bred with tdTomato Cre-reporter mice to yield the genotype [Nav1.8 ${ }^{\mathrm{Cre} /+}$; Rosa2 $\left.6^{\text {tdTomato/tdTomato }}\right]$, as described previously (Shields et al., 2012). Nav1.8-Cre mice were derived from breeding stock originally provided by the laboratory of John Wood (University College London) and tdTomato Cre-reporter mice (B6.Cg-

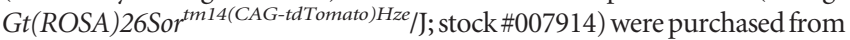
Jackson Laboratories.

$D R G$ culture. Adult mice ( $>4$ weeks old) were deeply anesthetized (ketamine/xylazine, 100/10 mg/kg) and DRG were isolated and dissociated as described previously (Dib-Hajj et al., 2009). Briefly, dissected ganglia were placed in ice-cold oxygenated complete saline solution (CSS), containing the following (in $\mathrm{mm}$ ): $137 \mathrm{NaCl}, 5.3 \mathrm{KCl}, 1 \mathrm{MgCl}_{2}, 25$ sorbitol, $3 \mathrm{CaCl}_{2}, 10$ HEPES, pH 7.2, and then transferred to an oxygenated $37^{\circ} \mathrm{C}$ CSS solution containing $95 \mu \mathrm{g} / \mathrm{ml}$ Liberase TM (containing highly purified collagenase I and II with a medium concentration of thermolysin; catalog \#05401127001; Roche Applied Science) and $0.6 \mathrm{~mm}$ EDTA and incubated with gentle agitation at $37^{\circ} \mathrm{C}$ for $20 \mathrm{~min}$, followed by $17 \mathrm{~min}$ in $95 \mu \mathrm{g} / \mathrm{ml}$ Liberase TL (containing highly purified collagenase I and II with a low concentration of thermolysin; Catalog \#05401020001; Roche Applied Science) and $30 \mathrm{U} / \mathrm{ml}$ papain (Worthington). The solution was aspirated and the ganglia triturated in DRG media (DMEM/F12 1:1) with $2 \mathrm{mM} \mathrm{L-glutamine} \mathrm{(Invitrogen),} 100 \mathrm{U} / \mathrm{ml}$ penicillin, $0.1 \mathrm{mg} / \mathrm{ml}$ streptomycin (Invitrogen), and 10\% fetal calf serum (Hyclone) containing $1.5 \mathrm{mg} / \mathrm{ml}$ bovine serum albumin (BSA; SigmaAldrich) and $1.5 \mathrm{mg} / \mathrm{ml}$ trypsin inhibitor (Roche Applied Science). The cell pellet was resuspended in DRG medium, placed on a cushion of $15 \%$ BSA in DRG medium, and centrifuged at $200 \times \mathrm{g}$ for 10 minutes to remove non-neuronal cells.

Compartmental chambers. Compartmental chamber cultures were prepared in a manner similar to that described by Campenot et al. (2009). Briefly, laminin-coated $35 \mathrm{~mm}$ (BD Biosciences) or $50 \mathrm{~mm}$ glass-bottom culture dishes (MatTek) were scraped with a pin-rake (200 $\mu \mathrm{M}$ width of pins; Tyler Research) to create a series of parallel tracks on the substrate, which delimited neuritic growth to the parallel lanes. A droplet of $0.4 \%$ methylcellulose in DMEM /F12 was spread to cover the scratched region where the Teflon divider barrier would be situated. Teflon dividers (Camp 7; Tyler Research) were attached to the culture dish with silicon grease (Dow Corning) to create three compartments (a central cell body compartment, flanked by peripheral compartments containing lanes in which neurites would extend). Dissociated DRG neurons were seeded in the central compartment and maintained in DRG medium. Peripheral compartments contained DRG medium supplemented with $100 \mathrm{ng} / \mathrm{ml}$ each of NGF (Alomone Labs) and GDNF (PeproTech) to promote neurite outgrowth. Chambers were maintained at $37^{\circ} \mathrm{C}$ in a humidified atmosphere containing $5 \% \mathrm{CO}_{2}$ and media in the central and peripheral compartments were changed every $3-4 \mathrm{~d}$.

Reagents and treatment of neurites. Rotenone, vincristine, oaubain, hydrogen peroxide $\left(\mathrm{H}_{2} \mathrm{O}_{2}\right)$, and TTX were purchased from SigmaAldrich and KB-R7943 from EMD Biosciences. Experimental reagents were added to peripheral compartments of the Campenot chambers after outgrowth of neurites into the peripheral compartment, which was 7-10 $\mathrm{d}$ following plating. At $3 \mathrm{~d}$ after treatment, half of the medium was replaced with fresh medium and experimental reagents were readministered. TTX was applied at a final concentration of $0.3 \mu \mathrm{M}$, a concentration that blocks TTX-sensitive sodium channels such as Nav1.6 and Nav1.7 (Cummins et al., 1998), which have been shown to be expressed along sensory axons and translocate to distal epidermal free nerve endings in the skin (Persson et al., 2010). KB-R7943 was applied at a final concentration of $0.5 \mu \mathrm{M}$, a concentration that preferentially blocks reverse and not forward sodium-calcium exchange ( $\mathrm{IC}_{50}$ reverse $0.3 \mu \mathrm{M}, \mathrm{IC}_{50}$ forward $17 \mu \mathrm{M}$; Watanabe et al., 2006) and that was used previously to demonstrate protective effects on DRG neurites (Persson et al., 2013). Treatment with rotenone, vincristine, ouabain, and $\mathrm{H}_{2} \mathrm{O}_{2}$ with or without TTX or KB-R7943 was studied simultaneously on sister compartments obtained from the same culture to insure that control and treatment groups were exposed to the same conditions. For all experiments, data were acquired from multiple compartments from two to three individual cultures.

Imaging and measuring of neurite lengths. Live-cell imaging of peripheral neurite compartments was performed using a Nikon Eclipse Ti microscope equipped with an environmental chamber (In Vivo Scientific) to maintain the cells in a humidified atmosphere at $37^{\circ} \mathrm{C}$. TdTomatopositive neurites were visualized with TRITC optics and images acquired with NIS-Elements software (Nikon). For each neurite compartment, large-field images of the entire compartment were acquired by stitching of individual fields of view. The mean neurite length for each compartment was assessed by measuring the length of the neurites from the central compartment barrier to the tip of the 10 longest neurites (Leinster et al., 2010). The fluorescent TdTomato reporter and live-cell imaging technique enabled each individual neurite compartment to be imaged before treatment and sequentially imaged at different posttreatment time points (i.e., days 3 and 6). For each individual neurite compartment, neurite length data at posttreatment time points (days 3 and 6) were normalized to pretreatment lengths (designated as 100) for that same compartment to account for variability in initial neurite lengths among compartments. Neurite length data at days 3 and 6 are presented as the mean normalized lengths of all compartments \pm SEM, where $n$ is the number of peripheral compartments.

Statistical analysis of neurite lengths. To determine the effect of a stressor (i.e., rotenone, vincristine, ouabain, and $\mathrm{H}_{2} \mathrm{O}_{2}$ ) on neurites, mean neurite lengths at posttreatment time points (days 3 and 6) were compared statistically with time-matched controls. Data for the timematched controls (untreated-, TTX-, and KB-R7943-only conditions) were obtained from a separate set of experiments (in the absence of a stressor: rotenone, vincristine, ouabain, or $\mathrm{H}_{2} \mathrm{O}_{2}$ ) at days 3 and 6. Statistical comparisons between time-matched groups (e.g., untreated versus rotenone-treated neurites or TTX- versus rotenone + TTX-treated neurites) were performed using Student's unpaired $t$ test with the significance level set at $p<0.05$.

To determine the neuroprotective effect of TTX and KB-R7943 on stressor-induced neurite degeneration, statistical comparisons were performed across different treatment conditions (e.g., rotenone, rotenone + TTX, and rotenone $+\mathrm{KB}-\mathrm{R} 7943$ ) within an experiment at equivalent posttreatment time points (days 3 and 6). Data were analyzed using one-way ANOVA followed by Tukey's post hoc test (for multiple group comparisons) and Student's unpaired $t$ test (for comparisons between two groups). Statistically significant differences $\left({ }^{*} p<0.05\right)$ or lack of statistical significance (n.s.) among conditions compared are indicated by connecting lines in Figures 2, 4, and 6 . 
Analysis of ATP levels. Intraneuritic levels of ATP were assessed using magnesium green (MgGreen) indicator (Leyssens et al., 1996; Baggaley et al., 2008). Isolated DRG neurons from $\mathrm{Na}_{\mathrm{V}} 1.8$ Cre tdTomato mice were cultured in Campenot chambers mounted on laminin-treated 50-mmdiameter glass bottom Petri dishes (MatTek) in DMEM:F-12 supplemented with $10 \%$ FBS, L-glutamine, penicillin/streptomycin, and pyruvate. At 7-10 d after plating, $1 \mu \mathrm{M}$ rotenone was administered to neurites in the peripheral compartments. After a 6 or $12 \mathrm{~h}$ incubation, MgGreen (15 $\mu \mathrm{M}$; Invitrogen) was added to the peripheral chambers and the cultures were incubated for $1 \mathrm{~h}$. Images were acquired with a Zeiss META 510 microscope using $488 \mathrm{~nm}$ (for MgGreen) and $543 \mathrm{~nm}$ (for tdTomato) laser lines and a $63 \times$ oil-immersion objective. The mean signal intensity over individual neurites was quantified for each condition ( $n=17$ for control, $n=21$ for $6 \mathrm{~h}$ rotenone, and $n=15$ for $12 \mathrm{~h}$ rotenone). Statistical comparisons among conditions were determined using one-way ANOVA followed by Tukey's post hoc test with the criterion for statistical significance set at $p<0.05$. Quantified ATP levels are presented as mean inverse values $\left(\mathrm{ATP}^{-1}\right)$ relative to control \pm SEM.

Quantification of ROS levels. ROS levels in neurites were measured with the oxidative stress indicator dye CM-H2DCFDA (Invitrogen). Control or rotenone-treated $(1 \mu \mathrm{M}, 20 \mathrm{~h})$ neurites were washed with DRG medium (without phenol red) and incubated in $1 \mu \mathrm{M} C M-$ $\mathrm{H} 2 \mathrm{DCFDA}$ for $45 \mathrm{~min}$ at $37^{\circ} \mathrm{C}$. Neurites were washed $3 \times$ in DRG medium (without phenol red) and imaged with a Nikon A1R-MP confocal microscope. Neurites were identified based on the tdTomato signal (blinded to the CM-H2DCFDA signal) and the CM-H2DCFDA fluorescence imaged with the $488 \mathrm{~nm}$ laser line. The mean signal intensity of individual neurites (ROI determined from the tdTomato signal) was quantified and averaged for each condition ( $n=23$ neurites for control, $n=30$ neurites for rotenone) and statistical comparisons were analyzed with Student's unpaired $t$ test $(p<0.05)$. Quantification was done blinded to the condition. Results are from three independent experiments and cultures.

Immunohistochemistry on skin tissue. From deeply anesthetized (ketamine/xylazine, $100 / 10 \mathrm{mg} / \mathrm{kg}$ ) $\mathrm{Na}_{\mathrm{V}} 1.8^{\mathrm{Cre} /{ }^{+}}$; Rosa26 $6^{\text {tdTomato/tdTomato }}$ mice (prepared for DRG culture), glabrous skin from the plantar surface of the hindpaws was dissected and postfixed overnight in a $0.1 \mathrm{M}$ phosphate buffer containing $4 \%$ formaldehyde and $14 \%$ picric acid $\left(4^{\circ} \mathrm{C}\right)$. The tissues were cryoprotected with $30 \%$ sucrose in $0.14 \mathrm{M}$ phosphate overnight at $4^{\circ} \mathrm{C}$, cryostat sectioned $(12 \mu \mathrm{m})$, and mounted on glass slides (SuperFrost Plus; Fischer). Slides were incubated in blocking solution (PBS containing 3\% fish skin gelatin (Sigma), 3\% normal donkey serum, and $0.3 \%$ Triton $\mathrm{X}-100$ ) for $1 \mathrm{~h}$ at room temperature. Sections were then incubated with a monoclonal mouse primary antibody against ubiquitin C-terminal hydrolase 1/Protein Gene Product 9.5 (PGP9.5) (1:1000; Encore) for $1 \mathrm{~d}$ at $4^{\circ} \mathrm{C}$, washed in PBS, incubated in secondary antibody donkey anti-mouse IgG-488 (Jackson ImmunoResearch) for $\sim 2 \mathrm{~h}$ at room temperature, washed in PBS, and mounted (Aqua-Poly/ Mount; Polysciences). Skin sections were then imaged with a Nikon A1R-MP confocal microscope in which PGP9.5 was imaged with the 488 $\mathrm{nm}$ laser line and tdTomato with the 561 laser line.

Immunocytochemistry on DRG neurites in vitro. Neurites in peripheral culture compartments were washed with PBS and fixed in $4 \%$ formaldehyde solution in $0.14 \mathrm{~m}$ Sorensen's phosphate buffer for 10 $\mathrm{min}$. After washing in PBS, neurites were incubated in blocking solution (see above) for $15 \mathrm{~min}$ and then primary antibody (goat antiNCX2, 1:100; Santa Cruz Biotechnology; mouse anti-pan sodium channel clone k58/35, 1:100; Sigma; or mouse anti- $\mathrm{Na}^{+} / \mathrm{K}^{+}$-ATPase $\beta, 1: 100$; Genetex for $2 \mathrm{~h}$ at room temperature). After washing in PBS, neurites were incubated in secondary antibody (donkey anti-goat IgG-488 or donkey-mouse IgG-488; Jackson ImmunoResearch). Images of neurites were acquired with Nikon C1si confocal microscope and EZ-C1 software (Nikon).

Cell death quantification. Cell death was assayed by the detection of propidium iodide (PI) fluorescence in neuronal nuclei. PI $(10 \mu \mathrm{g} / \mathrm{ml})$ was added to the center compartment of the Campenot chambers (containing the cell bodies) and incubated for $35 \mathrm{~min}$ at $37^{\circ} \mathrm{C}$. After incubation with PI, medium was replaced and the center compartments were imaged with a Nikon A1R-MP confocal microscope operating in spectral detection mode (separating emission spectra for tdTomato and PI). Images were acquired with a $10 \times$ objective and the percentage of neurons with PI-labeled nuclei was calculated. The permeabilizing agent, digitonin $(0.2 \% \mathrm{w} / \mathrm{v}$; Sigma) was used as a positive control for PI labeling of nuclei. Statistical comparisons between control and rotenone-treated cultures were analyzed using Student's unpaired $t$ test $(p<0.05 ; n=21$ fields of view for control and $n=21$ fields of view for rotenone) from three independent cultures. Quantification was done blinded to the condition.

$\mathrm{Ca}^{2+}$ imaging in neurites. $\mathrm{Ca}^{2+}$ levels in neurites were assayed using the ratiometric intracellular calcium indicator Fura-2-AM (Invitrogen). Neurites in peripheral culture compartments were loaded with $2 \mu \mathrm{M}$ Fura-2-AM in standard bath solution (SBS) containing the following (in mM): $140 \mathrm{NaCl}, 3 \mathrm{KCl}, 1 \mathrm{MgCl}_{2}, 1 \mathrm{CaCl}_{2}$, and 10 HEPES, pH 7.3, 320 mOsm, with $0.02 \%$ Pluronic (Invitrogen) at room temperature for $2 \mathrm{~h}$. Neurites were illuminated every $2 \mathrm{~s}$ with alternatively 340 , 380, and 554 nm light using a Nikon Ti-E inverted microscope equipped with a fastswitching xenon light source (Lambda DG-4; Sutter Instruments), a UVtransmitting $40 \times$ objective (1.3 numerical aperture, oil-immersion, Super Fluor; Nikon) and a $1.5 \times$ optical zoom. Intact neurites identified from the tdTomato signal (blinded to the Fura-2 signals) were selected for $\mathrm{Ca}^{2+}$ imaging and images were captured using a QuantEM CCD camera (Princeton Instruments).

Stimulation protocol for $\mathrm{Ca}^{2+}$ imaging. Peripheral culture chamber compartments containing neurites were microperfused at a constant flow rate using a computerized valve system (ValveLink 8.2; AutoMate Scientific). To measure $\mathrm{Ca}^{2+}$ transients in activated neurites, membrane depolarization was induced by perfusion with high $\left[\mathrm{K}^{+}\right]$solution (SBS containing $140 \mathrm{~mm} \mathrm{KCl} / 10 \mathrm{~mm} \mathrm{NaCl}$ ) according to the following perfusion protocol (in seconds from start of image acquisition): (30) SBS, (90) high $\left[\mathrm{K}^{+}\right]$solution, and (150) SBS.

$\mathrm{Ca}^{2+}$ imaging data analysis. Acquired images were digitized and analyzed with NIS-Elements software (Nikon). Based on tdTomato signal, images were thresholded and a binary mask created over tdTomatopositive neurites. For each neurite studied, an $\sim 50-\mu \mathrm{m}$-long segment of the binary mask overlying the neurites was defined as the ROI and, for each time frame, the $F_{340}$ and $F_{380}$ mean pixel intensity were measured $\left(F_{340}\right.$ and $F_{380}$ represent Fura- 2 emission intensities measured with 340 and $380 \mathrm{~nm}$ excitation, respectively) and background correction performed. The ratio of $F_{340} / F_{380}$ was calculated for each time frame and average values from all recorded neurites are presented in graphs. Two sets of experiments were performed, the first comparing control $(n=23)$ and rotenone-treated $(n=23)$ and the second comparing rotenone$(n=13)$ and rotenone $+\operatorname{TTX}(n=17)$-treated neurites. Comparisons between $R_{340 / 380}$ values were made within each set of experiments and not between the different sets of experiments due to different exposure settings between the two sets of experiments. The clearance of cytosolic $\mathrm{Ca}^{2+}$ was measured as area under the curve (AUC) from the time of $t=$ $105 \mathrm{~s}$ to $t=200 \mathrm{~s}$ and differences between groups were analyzed using Student's unpaired $t$ test with the criterion for statistical significance set at $p<0.05$.

\section{Results}

\section{In vitro model of axonal degeneration}

To study axonal degeneration in vitro, we used a model system of cultured DRG neurons. Axons projecting from DRG neurons are known to degenerate in multiple peripheral neuropathies (Pardo et al., 2001; England and Asbury, 2004; Pavlakis et al., 2012); for example, in some sensory neuropathies, small diameter- $(\mathrm{C}$ - and $\mathrm{A} \delta$-) fibers that project to the epidermal layer of the skin appear to be particularly prone to degeneration (Lacomis, 2002; Bednarik et al., 2009; Tavee and Zhou, 2009). Peripheral sensory axons targeted to the skin have been shown to express sodium channel $\mathrm{Na}_{\mathrm{V}} 1.8$ (Persson et al., 2010; Shields et al., 2012). To study these $\mathrm{Na}_{\mathrm{V}} 1.8$-expressing neurons, we used the Cre-lox recombination system, crossing $\mathrm{Na}_{\mathrm{V}} 1.8^{-/ \mathrm{Cre}}$ mice with Rosa26 floxed-stop tdTomato-expressing reporter mice, inducing expression of the red fluorescent tdTomato protein in $\mathrm{Na}_{\mathrm{V}} 1.8$ - 
A
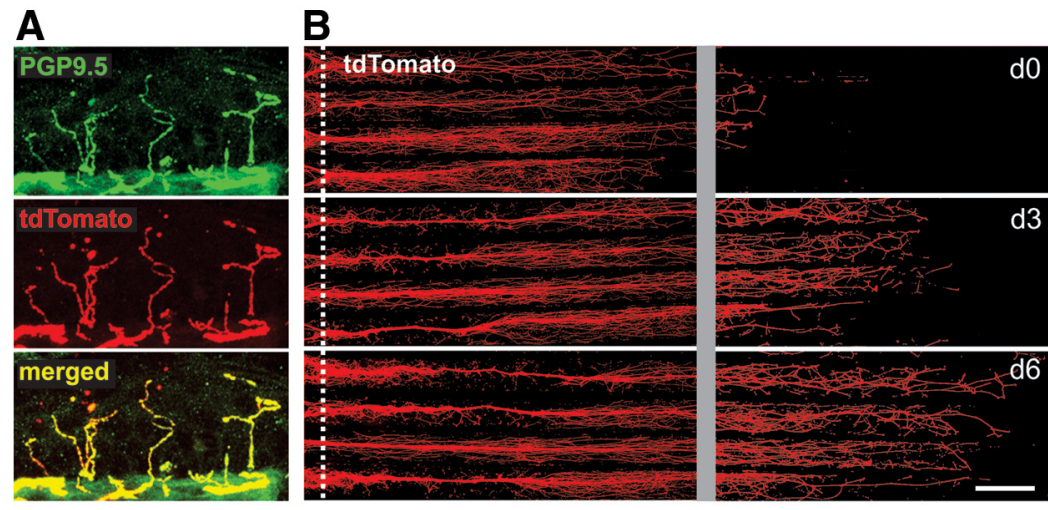

Figure 1. Expression of tdTomato reporter in DRG neurons. $\boldsymbol{A}$, The skin of Nav1.8-cre/tdTomato mice exhibits tdTomato reporter (red) in PGP9.5 (green)-positive intraepidermal nerve fibers (IENFs). Colocalization of tdTomato and PGP9.5 (yellow) demonstrates that virtually all IENFs express tdTomato label. $\boldsymbol{B}$, tdTomato reporter (red) is displayed by neurites within peripheral compartment of Campenot chamber. Proximal boundary of peripheral chamber is indicated by dotted white line. Approximately 1 week after culturing of DRG neurons in the central compartment, neurites have emerged from under the chamber barrier. Neurites continue to extend from day 0 (d0) to day 6 (d6). To visualize individual fine neurite endings, brightness/contrast was increased uniformly for d0, d3, and d6 panels in the distal-most part of chamber (to the right of gray gutter). Scale bar, $500 \mu \mathrm{m}$.

expressing cells (Shields et al., 2012). Figure $1 A$ demonstrates the presence of tdTomato reporter protein within the nerve terminals (identified with PGP9.5 immunoreactivity) in the epidermis of $\mathrm{Na}_{\mathrm{V}} 1.8^{-/ \mathrm{Cre}} / \mathrm{tdT}$ Tomato mice.

Axons in vivo may be confronted with vastly different microenvironments compared with cell bodies, such as, for example, the distal ends of sensory nerve fibers that terminate as naked nerve endings in the epidermis compared with the satellite cell-ensheathed cell bodies located within the DRG, which can be located $>1 \mathrm{~m}$ distant. To establish a model system that allows selective targeting of neurites without direct action on cell bodies, we used a compartmented culturing system (Campenot, 1977; Campenot et al., 2009). DRG neurons from adult $\mathrm{Na}_{\mathrm{V}} 1.8$-Cre tdTomato mice were seeded in the central compartment of the culturing chambers and, attracted by growth factors, neurites extended into the peripheral compartments. The tdTomato protein was expressed and transported along the growing neurites so that visualization of the tdTomato signal using fluorescence microscopy permitted sequential live assessment of neurite lengths. Neurites exhibited a linear growth pattern along the scored lanes of the substrate within the peripheral culture compartment (Fig. 1B). Seven to $10 \mathrm{~d}$ after plating, neurites had extended a considerable distance into the peripheral compartment and selective application of experimental reagents to neurites (and not to cell bodies, which were located in the central compartment) could be performed. In nonexperimentally treated peripheral compartments, neurites exhibited continued growth throughout the $6 \mathrm{~d}$ of experiments (Fig. 1B).

\section{Mitochondrial complex I inhibitor rotenone induces neurite degeneration when targeted to neurites}

Mitochondrial dysfunction has been associated with multiple neurodegenerative disorders in the CNS and in peripheral neuropathies (Courchesne et al., 2011; Court and Coleman, 2012). To examine neurite integrity in response to impairment of mitochondrial function in an in vitro model of peripheral axonal degeneration, we selectively exposed neurites to the mitochondrial complex I inhibitor rotenone, which causes disruption of the electron transport chain. As demonstrated in Figure $2 A, 1 \mu \mathrm{M}$ rotenone administered to neurites induced substantial neurite degeneration at day 3 and a nearly complete degeneration of neurites at day 6 after treatment. Comparison of rotenone-treated neurites (Fig. 2B) with untreated time-matched control neurites (Fig. $2 F$ ) demonstrates that rotenone induced significant neurite degeneration at days 3 and 6 compared with time-matched controls (rotenone: day 3, $19.8 \pm 3.9 ;$ day $6,9.2 \pm 1.9$ vs control: day 3, $119.5 \pm 13.6$; day 6, $140.7 \pm 15.7$; Student's unpaired $t$ test; $p<0.05$ ), producing decreases in neurite lengths of $\sim 83 \%$ and $\sim 93 \%$ at days 3 and 6 , respectively. Rotenone applied to one side compartment did not cause neurite degeneration in the contralateral compartment (data not shown).

\section{Sodium channels contribute to} rotenone-induced neurite degeneration Previous studies on whole nerve preparations from CNS and PNS have shown that sodium channel activity contributes to axonal dysfunction under conditions of energetic stress induced by anoxia (Stys et al., 1992; Fern et al., 1993; Lehning et al., 1996). As demonstrated in Figure 2E, neurites within the peripheral compartments of Campenot chambers exhibit robust voltage-gated sodium channel immunoreactivity along their lengths, establishing that sodium channels are translated and transported to the neurites in our system.

To study the effect of rotenone on neurites under conditions of sodium channel blockade, we administered rotenone to neurites simultaneously with the sodium channel blocker TTX at a concentration of $0.3 \mu \mathrm{M}$ (a dose known to block TTX-sensitive sodium currents; Catterall et al., 2005). As seen in Figure 2A, treatment with rotenone in the presence of TTX caused reduced neurite lengths at 3 and $6 \mathrm{~d}$ after treatment. Time-matched comparisons demonstrated that neurites treated with rotenone + TTX (Fig. 2B) exhibited significant neurite degeneration at days 3 and 6 compared with TTX-treated controls (rotenone + TTX: day $3,50.8 \pm 7.3$; day $6,37.7 \pm 10.1$ vs TTX: day $3,117.9 \pm 10.5$; day 6, $122.8 \pm 11.1$; Student's unpaired $t$ test, $p<0.05$; Fig. $2 F$ ), producing decreases in neurite lengths of $\sim 57 \%$ and $\sim 69 \%$ at days 3 and 6 , respectively. The decreases in neurite lengths after rotenone + TTX treatment were smaller than those after treatment with rotenone alone $(\sim 83 \%$ and $\sim 93 \%$ reductions at days 3 and 6, respectively). To determine statistically whether TTX exerts a protective effect on rotenone-induced neurite degeneration, comparisons across treatment conditions were performed (Fig. $2 B$ ). As demonstrated in Figure $2 B$, TTX, when coadministered with rotenone, significantly protected neurites from rotenone-induced degeneration at days 3 and $6(p<0.05)$. Together, these analyses demonstrate that TTX did not completely inhibit rotenone-induced neurite degeneration, but exerted a partial protective effect on rotenone-exposed neurites.

Control experiments and subsequent across-group comparisons of untreated controls and TTX-only conditions demonstrated that blockade of sodium channels with TTX did not alter neurite growth in the absence of rotenone. Neurites in peripheral chambers treated with TTX displayed mean neurite lengths that were not statistically different from those of neurites in untreated peripheral chambers at days 3 and 6 after treatment $(p=0.99$; Fig. $2 F)$. 
A

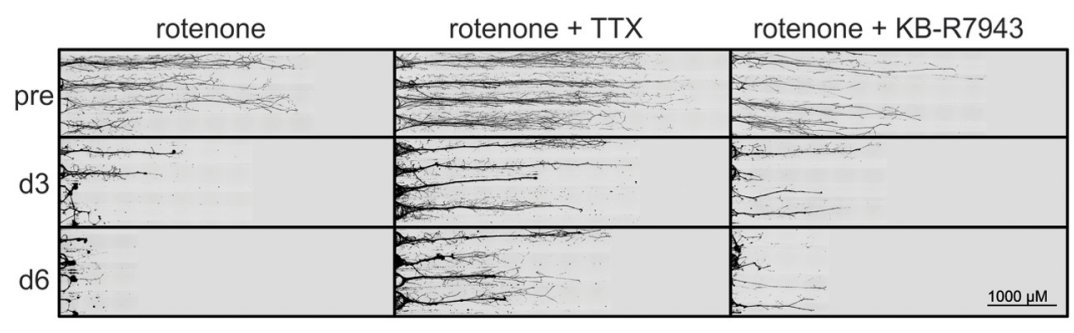

C

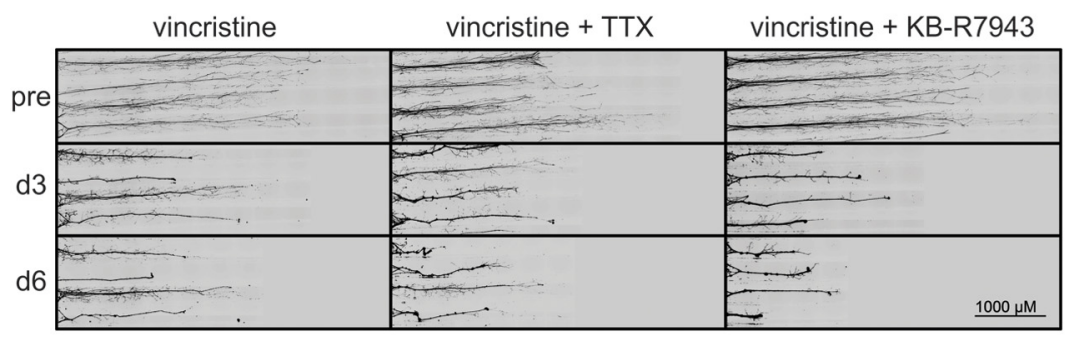

E

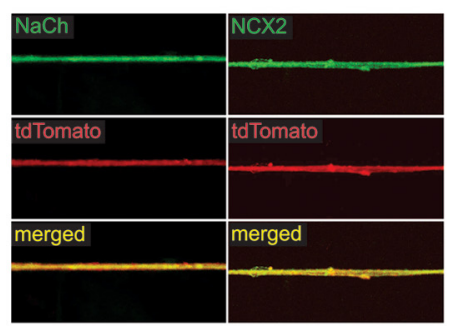

F
B

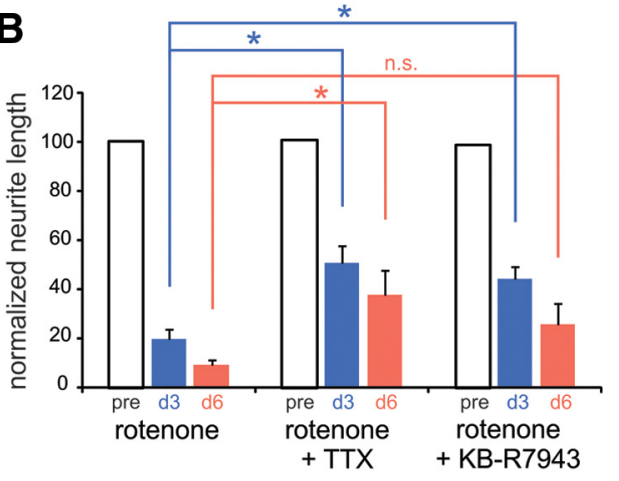

D

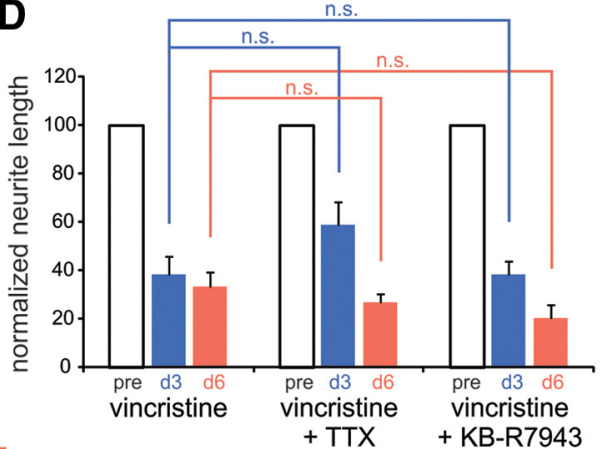

Figure 2. Rotenone- and vincristine-induced neurite degeneration. $\boldsymbol{A}$, Exposure of neurites to rotenone (1 $\mu \mathrm{m})$ induces substantial degeneration at day 3 and nearly complete degeneration at day 6 after administration. Blockade of sodium channels with TTX $(0.3 \mu \mathrm{m})$ and reverse NCX activity with KB-R7943 $(0.5 \mu \mathrm{m})$ partially protects rotenone-treated neurites from degeneration. $\boldsymbol{B}$, Across-treatment-group comparisons demonstrates that TTX provides significant protection from rotenone-induced degeneration at days 3 and 6 , whereas KB-R7943 provides significant protection at day 3 after treatment only ( ${ }^{*} p<0.05$ compared with equivalent day of rotenone treatment only, n.s. $=$ not significant; $n=7,6$, and 7 compartments for rotenone, rotenone + TTX, and rotenone + KB-R7943 conditions, respectively). Neurite lengths are normalized to pretreatment lengths (pre) for each individual neurite compartment at days 3 and 6 , respectively. $C$, Exposure of neurites to vincristine induces substantial degeneration at day 3 after administration and increased degeneration at day 6 . TTX and KB-R7943 treatment does not provide a protective effect on vincristine-induced neurite degeneration at day 3 or day 6 after administration. D, Across-treatment-group comparisons demonstrate that TTX and KB-R7943 do not provide significant protection from vincristine-induced neurite degeneration at days 3 and 6 (not significant, n.s.; compared with equivalent day for vincristine only; $n=7,8$, and 5 compartments for vincristine, vincristine + TTX, and vincristine + KB-R7943 conditions, respectively). Neurite lengths are normalized to pretreatment lengths (pre) for each individual neurite compartment at days 3 and 6 , respectively. $\boldsymbol{E}$, Neurites of DRG neurons from Nav1.8-Cre/tdTomato mice within peripheral culture chamber compartments exhibit sodium channel (green; top left) and NCX2 (green; top right) immunoreactivity. $\boldsymbol{F}$, Control neurites treated with TTX or KB-R7943 exhibit continued growth at days 3 and 6 after administration, demonstrating that blockade of sodium channels with TTX or of reverse NCX with KB-R7943 does not alter the temporal distribution of neurite lengths compared with equivalent day of control; (not significant, n.S.; $n=4$ compartments each for control, control + TTX, and control + KB-R7943 conditions). Data are presented as mean \pm SEM.

\section{Inhibiting reverse $\left(\mathrm{Ca}^{2+}\right.$-importing) mode of $\mathrm{NCX}$ protects} rotenone-exposed neurites from degeneration

NCX is an antiporter membrane protein and an important contributor to $\mathrm{Na}^{+} / \mathrm{Ca}^{2+}$ homeostasis of cells. Under normal conditions, NCX operates in a forward mode, extruding $\mathrm{Ca}^{2+}$ from the cell in exchange for $\mathrm{Na}^{+}$. However, elevated intracellular $\mathrm{Na}^{+}$concentrations can drive reverse $\left(\mathrm{Ca}^{2+}\right.$-importing) mode of NCX, which can lead to $\mathrm{Ca}^{2+}$-driven injury. As demonstrated in Figure 2E, neurites in the peripheral compartment displayed NCX2 immunolabeling. To determine whether reverse, $\mathrm{Ca}^{2+}$ importing operation of NCX can contribute to rotenoneinduced neurite degeneration in our in vitro model of axonal degeneration, we treated neurites with $0.5 \mu \mathrm{M} \mathrm{KB}-\mathrm{R} 7943$, a concentration that selectively inhibits the reverse mode of NCX (Watanabe et al., 2006) and that was used previously to demonstrate protective effects on DRG neurites (Persson et al., 2013).

As demonstrated in Figure $2 A$, treatment with rotenone in the presence of KB-R7943 caused reduced neurite lengths at days 3 and 6 after treatment. Time-matched comparisons demonstrated that neurites treated with rotenone + KB-R7943 (Fig. 2B) exhibited significant neurite degeneration at days 3 and 6 compared with KB-R7943-treated controls (rotenone + KB-R7943: day 3, $44.3 \pm 5.2$; day 6, $25.8 \pm 8.4$ vs KB-R7943: day 3, $129.7 \pm 8.0$; day $6,152.5 \pm 5.2$; Student's unpaired $t$ test, $p<0.05$; Fig. $2 F)$, 
A

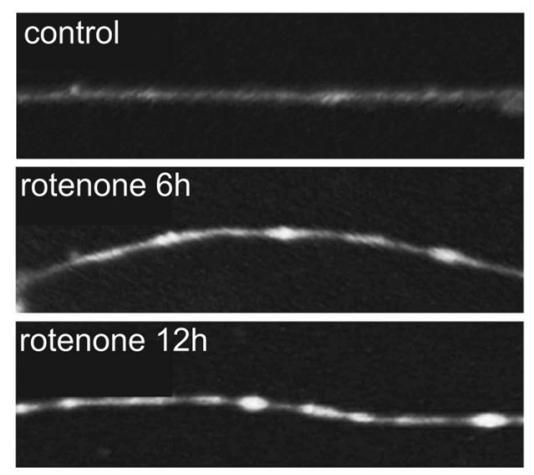

B

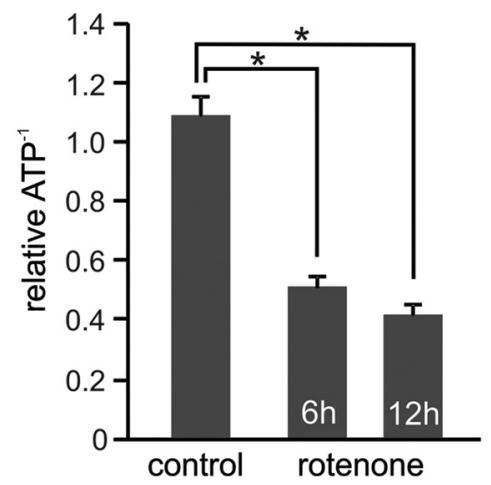

Figure 3. Rotenone reduces cellular ATP levels in DRG neurites. $\boldsymbol{A}$, Control neurites exhibit low levels of MgGreen fluorescence (inverse of ATP levels). Rotenone treatment of neurites for 6 and $12 \mathrm{~h}$ induces increased $\mathrm{MgGreen}$ fluorescence, indicating reduced levels of ATP. B, Quantification of MgGreen signal indicates a significant $\sim 50 \%$ reduction in relative ATP levels at $6 \mathrm{~h}$ and additional reduction of ATP levels at $12 \mathrm{~h}$ after rotenone exposure $\left({ }^{*} p<0.05\right.$ compared with control; $n=17,21$, and 15 neurites for control, $6 \mathrm{~h}$ rotenone, and $12 \mathrm{~h}$ rotenone conditions, respectively). Data are presented as mean inverse values $\pm \mathrm{SEM}$.

producing decreases in neurite lengths of $\sim 66 \%$ and $\sim 83 \%$ at days 3 and 6, respectively. To evaluate statistically whether KBR7943 protects neurites from rotenone-induced degeneration, comparisons across treatment conditions were performed (Fig. $2 B$ ). As demonstrated in Figure $2 B, \mathrm{~KB}-\mathrm{R} 7943$, when coadministered with rotenone, significantly protected neurites from rotenoneinduced degeneration at day $3(p<0.05)$. At day 6, however, KB-R7943 did not exert a protective action on rotenone-induced neurite degeneration ( $p=0.19$; Fig. $2 B$ ). Together, these analyses show that KB-R7943 did not completely inhibit rotenoneinduced neurite degeneration, but did exert a partial protective effect on rotenone-treated neurites at an initial (day 3) but not later (day 6) posttreatment time point.

Control experiments and subsequent across-group comparisons of untreated controls and KB-R7943-only conditions demonstrated that blockade of reverse NCX activity with KB-R7943 did not alter neurite growth in the absence of rotenone. Neurites in peripheral chambers treated with KB-R7943 displayed mean neurites lengths that were not statistically different from those of neurites in untreated peripheral chambers at individual posttreatment time points $(p=0.80$; Fig. $2 F)$.

\section{Sodium channel and NCX inhibitors do not protect from vincristine-induced neurite degeneration}

In addition to mitochondrial dysfunction, axonal neuropathies have been linked to impaired axonal transport resulting from damage to microtubules (Millecamps and Julien, 2013). For example, the microtubule disrupting, chemotherapeutic agent vincristine induces severe sensory neuropathies in many patients and neurite degeneration in explant DRG cultures (Wang et al., 2000; Boyette-Davis et al., 2013). However, it is not known whether the activities of sodium channels and/or reverse NCX participate in the vincristine-induced axonal degeneration. Vincristine $(10 \mu \mathrm{M})$ administered to neurites resulted in reduced neurite lengths at days 3 and 6 after treatment (Fig. 2C). Timematched comparisons demonstrated that neurites treated with vincristine (Fig. 2D) exhibited significant neurite degeneration at days 3 and 6 compared with untreated controls (vincristine: day $3,38.4 \pm 7.4$; day $6,33.4 \pm 5.9$ vs control: day $3,119.5 \pm 13.6$; day $6,140.7 \pm 15.7$; Student's unpaired $t$ test, $p<0.05$; Fig. $2 F)$, producing decreases in neurite lengths of $\sim 68 \%$ and $\sim 76 \%$ at days 3 and 6 , respectively.
In contrast to rotenone-induced neurite degeneration, vincristine-induced degeneration was not attenuated with coadministration of TTX or KB-R7943 (Fig. 2C). Statistical comparisons of vincristine + TTX-treated neurites (Fig. 2D) with TTX-treated time-matched controls (Fig. 2F) demonstrated that vincristine coadministered with TTX induced significant neurite degeneration at days 3 and 6 (vincristine + TTX: day 3, $58.8 \pm$ 9.7; day $6,27.1 \pm 3.1$ vs TTX: day 3, $117.9 \pm 10.5$; day $6,122.8 \pm 11.1$; Student's unpaired $t$ test, $p<0.05$ ), producing decreases in neurite lengths of $\sim 50 \%$ and $\sim 78 \%$ at days 3 and 6 , respectively. Similar comparisons of vincristine + KB-R7943-treated neurites (Fig. 2D) with KB-R7943-treated timematched controls (Fig. 2F) demonstrated that vincristine coadministered with KB-R7943 induced significant neurite degeneration at days 3 and 6 (vincristine + KB-R7943: day 3, $38.6 \pm 5.0$; day 6, $20.3 \pm 5.7$ vs KB-R7943: day 3, $129.7 \pm 8.0$; day 6, $152.5 \pm 5.2$; Student's unpaired $t$ test, $p<0.05)$, producing decreases in neurite lengths of $\sim 70 \%$ and $\sim 87 \%$ at days 3 and 6 , respectively. Across-treatment-group comparisons of neurite lengths after treatment with vincristine, vincristine + TTX, and vincristine + KB-R7943 are shown in Figure 2D and demonstrate that blockade of sodium channels with TTX did not protect vincristine-treated neurites from degenerating at day 3 $(p=0.20$ compared with vincristine treatment only) or day 6 ( $p=0.60$ compared with vincristine treatment only). Similarly, KB-R7943 treatment did not provide protection from vincristine-induced degeneration at day $3(p=1$ compared with vincristine treatment only) or day 6 ( $p=0.20$ compared with vincristine treatment only).

\section{Intraneuritic ATP levels are reduced in rotenone- treated neurites}

Rotenone application has been shown previously to reduce ATP levels in dissociated DRG cultures (Press and Milbrandt, 2008). To establish whether rotenone treatment targeted selectively to neurites attenuates intraneuritic levels of ATP, the MgGreen assay was used. MgGreen indirectly measures the change in cellular ATP concentration, with ATP reduction seen as increased fluorescence intensity (Leyssens et al., 1996; Baggaley et al., 2008). As demonstrated in Figure $3 A, 6$ and $12 \mathrm{~h}$ of rotenone treatment led to increased signal intensity of MgGreen in the neurites, indicating reduced levels of cellular ATP. Quantification of MgGreen signal intensity over individual neurites demonstrates a significant decrease in cellular ATP levels at $6 \mathrm{~h}$ after rotenone treatment $(0.51 \pm 0.04)$ and a further reduction at $12 \mathrm{~h}$ after treatment $(0.41 \pm 0.04$ a.u. $)$ compared with control values $(1.1 \pm 0.07$ a.u.; $p<0.05$; Fig. $3 B)$.

\section{Impaired function of $\mathrm{Na}^{+} / \mathrm{K}^{+}$ATPase induces neurite degeneration that is attenuated by blockade of sodium channels}

$\mathrm{Na}^{+} / \mathrm{K}^{+}$-ATPase is crucial for maintaining the ionic homeostasis and the resting membrane potential of neurons and its operation requires ATP. Neurites in the peripheral culture compartment exhibited robust $\mathrm{Na}^{+} / \mathrm{K}^{+}$-ATPase immunolabeling (Fig. 4A). To 
A

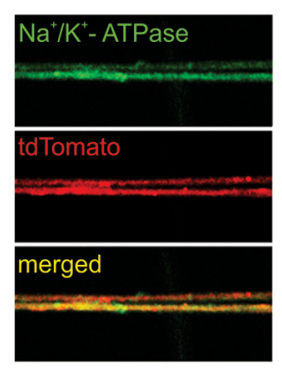

B

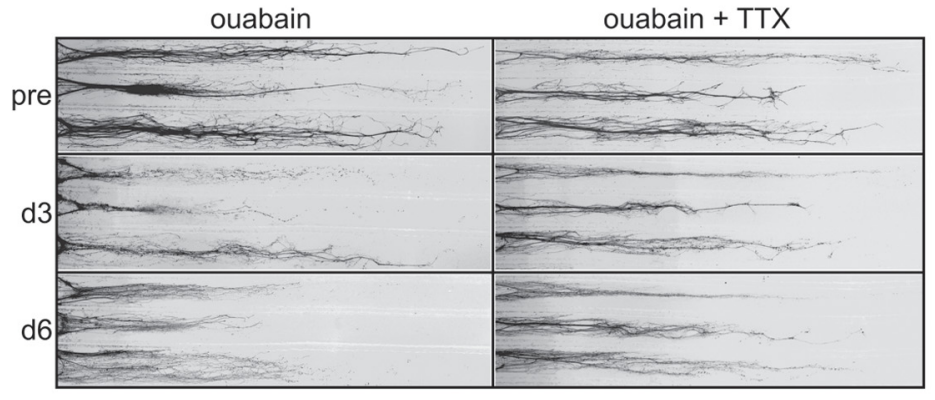

C

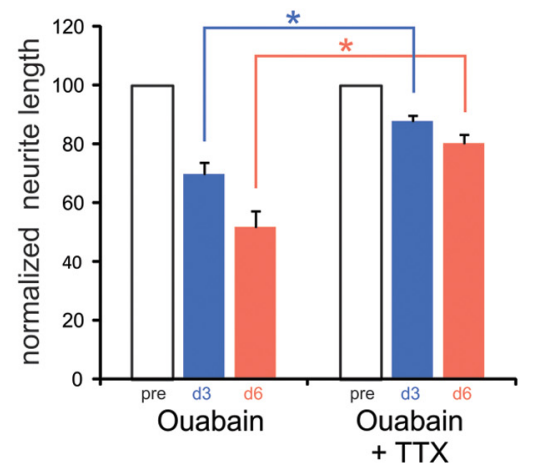

Figure 4. Neurite degeneration induced by inhibition of $\mathrm{Na}^{+} / \mathrm{K}^{+}$-ATPase is protected by sodium channel blockade. $\boldsymbol{A}$, Neurites of DRG neurons from Nav1.8-Cre/tdTomato mice within peripheral culture chamber compartments exhibit $\mathrm{Na}^{+} / \mathrm{K}^{+}$-ATPase (green) immunolabeling. $\boldsymbol{B}$, Inhibition of Na ${ }^{+} / \mathrm{K}^{+}$-ATPase activity with $250 \mu \mathrm{M}$ ouabain induces substantial neurite degeneration at day 3 and increased degeneration at day 6 after treatment. $C$, Across-treatment-group comparisons demonstrates that TTX provides significant protection from ouabain-induced degeneration at days 3 and 6 after treatment $\left({ }^{*} p<0.05\right.$ compared with equivalent day for ouabain only, n.s. $=$ not significant; $n=15$ and 19 compartments for ouabain and ouabain + TTX conditions, respectively). Neurite lengths are normalized to pretreatment lengths (pre) for each individual neurite compartment at days 3 and 6 , respectively. Data are presented as mean \pm SEM.

mimic rotenone-induced attenuated $\mathrm{ATP}$ levels and a subsequent reduced capacity of the $\mathrm{Na}^{+} / \mathrm{K}^{+}$-ATPase, we blocked $\mathrm{Na}^{+} / \mathrm{K}^{+}$ATPase with $250 \mu \mathrm{M}$ ouabain. Figure $4 B$ demonstrates that selective administration of ouabain to neurites caused a reduction in neurite lengths at days 3 and 6 after treatment. Time-matched comparisons demonstrated that neurites treated with ouabain (Fig. 4C) exhibited significant degeneration at days 3 and 6 compared with untreated control neurites (ouabain: day 3, 69.6 \pm 4.4; day $6,52.1 \pm 5.3$ vs control: day $3,119.5 \pm 13.6$; day $6,140.7 \pm$ 15.7; Student's unpaired $t$ test, $p<0.05$; Fig. $2 F)$, producing decreases in neurite lengths of $\sim 42 \%$ and $\sim 63 \%$ at days 3 and 6 , respectively.

To determine the contribution of sodium channels to ouabaininduced neurite degeneration, we coadministered TTX and ouabain to neurites. Time-matched comparisons demonstrated that neurites treated with ouabain + TTX (Fig. 4C) exhibited significant neurite degeneration at days 3 and 6 compared with TTX-treated controls (Fig. $2 F$ ) (ouabain + TTX: day 3, 87.9 \pm 2.0 ; day 6, $80.4 \pm 3.0$ versus TTX: day 3, $117.9 \pm 10.5$; day 6, $122.8 \pm 11.1$; Student's unpaired $t$ test, $p<0.05$ ), producing decreases in neurite lengths of $\sim 25 \%$ and $\sim 35 \%$ at days 3 and 6 , respectively.

Figure $4 B$ demonstrates a protective effect of TTX on ouabain-induced neurite degeneration at days 3 and 6 after treatment (Fig. 4B). To determine statistically whether TTX exerted a protective effect on ouabain-exposed neurites, comparisons across treatment conditions were performed. As demonstrated in Figure $4 C$, TTX significantly protected neurites from ouabaininduced degeneration at days 3 and $6(p<0.05)$. Together, these analyses show that TTX did not completely inhibit ouabaininduced neurite degeneration, but provided a partial protection of ouabain exposed neurites.

In a separate set of experiments, we examined the effect of KB-R7943 on ouabain-induced neurite degeneration. In this set of experiments, neurites treated with ouabain displayed significant degeneration at days 3 and 6 compared with timematched untreated controls (ouabain: day 3, $40.4 \pm 3.0$; day 6, $31.3 \pm 2.9$ vs control: day $3,119.5 \pm 13.6$; day $6,140.7 \pm 15.7$; Student's unpaired $t$ test, $p<0.05$ ), producing decreases in neurite lengths of $\sim 66 \%$ and $\sim 78 \%$ at days 3 and 6 , respectively. Neurites treated with ouabain + KB-R7943 demonstrated significant degeneration at days 3 and 6 compared with time-matched KB-R7943-treated controls (ouabain + KB-
A

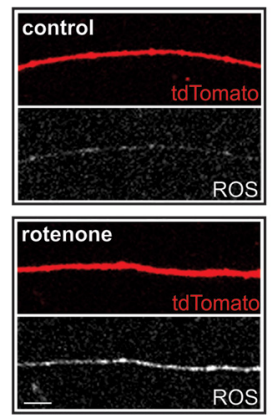

B

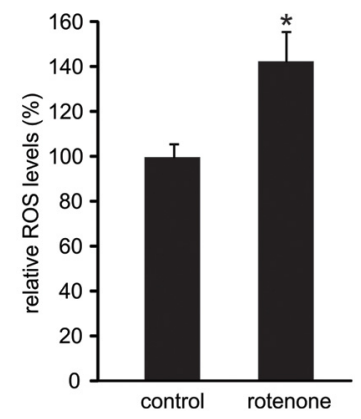

Figure 5. Rotenone increases ROS levels in DRG neurites. $A$, Levels of ROS were assayed using the ROS-sensitive fluorescent dye $\mathrm{CM}-\mathrm{H}_{2} D C F D A$. Control neurites exhibited low levels of ROS fluorescence (white) and neurites display substantially greater fluorescence after $20 \mathrm{~h}$ of rotenone treatment. Scale bar, $10 \mu \mathrm{m}$. B, Quantification of dye signals indicates a significant increase in ROS levels after rotenone treatment compared with control neurites ( ${ }^{*} p<0.05 ; n=$ 23 and 30 neurites for control and rotenone conditions, respectively). Data are presented as mean \pm SEM.

R7943: day 3, $55.2 \pm 5.2$; day 6, $42.3 \pm 3.7$ vs KB-R7943: day 3, $129.7 \pm 8.0$; day $6,152.5 \pm 5.2$; Student's unpaired $t$ test, $p<$ 0.05 ), producing decreases in neurite lengths of $\sim 58 \%$ and $\sim 72 \%$ at days 3 and 6, respectively. Across treatment condition analyses revealed that KB-R7943 significantly protected neurites from ouabain-induced degeneration at days 3 and $6(p<0.05)$.

\section{Elevated ROS levels in rotenone-treated neurites}

In addition to impaired ATP production, rotenone has also been shown to cause elevated levels of ROS in neurites when administered to dissociated DRG cultures (Press and Milbrandt, 2008). To determine whether rotenone elevates ROS levels when targeted specifically to neurites, we measured intraneuritic ROS levels using the oxidative stress indicator dye CM-H2DCFDA. As demonstrated in Figure $5 A$, tdTomato-positive neurites exposed to $1 \mu \mathrm{M}$ rotenone for $20 \mathrm{~h}$ (with no rotenone in the central compartment containing all cell bodies) exhibited enhanced CM-H2DCFDA signal compared with control neurites. Quantification of CM-H2DCFDA signal intensities from tdTomato-positive neurites revealed $\sim 43 \%$ greater ROS levels in rotenone-treated neurites (142.8 $\pm 12.8 \%)$ compared with untreated control neurites $(99.9 \pm 6.0 \%, p<0.05$; Fig. 5B). 
A

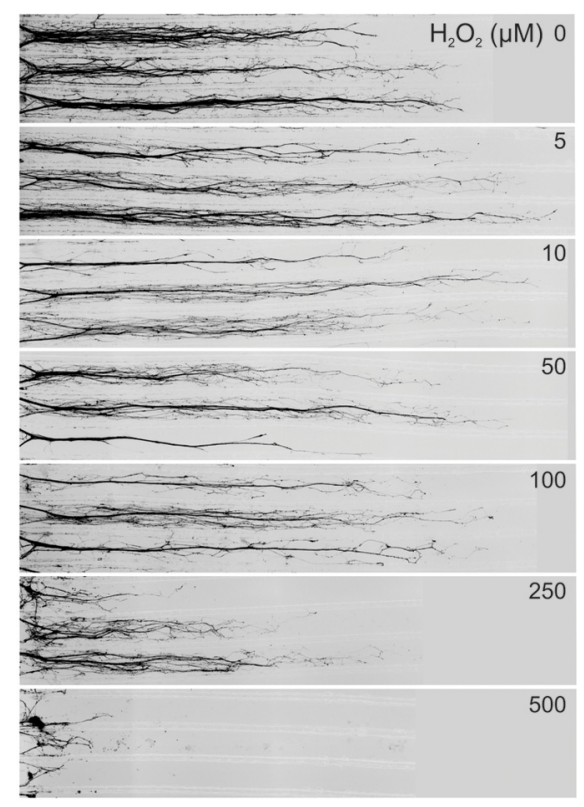

B
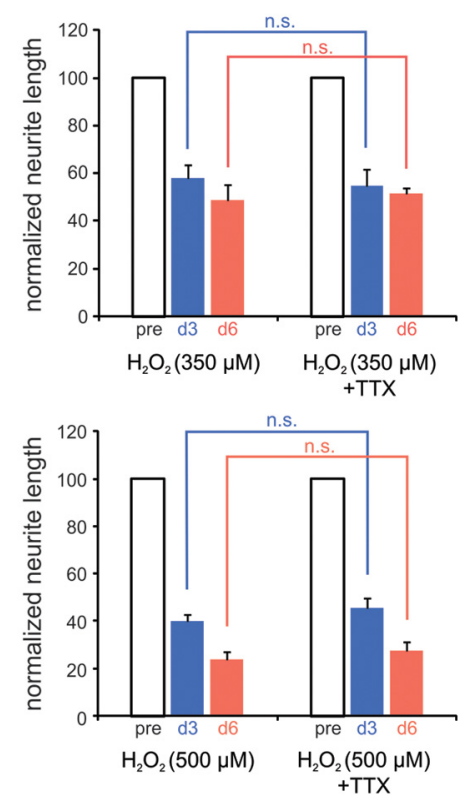

Figure 6. Oxidant treatment induces neurite degeneration. $A$, Titer series of the oxidant $\mathrm{H}_{2} \mathrm{O}_{2}$ demonstrates minimal neurite degeneration at day 3 after treatment with $\mathrm{H}_{2} \mathrm{O}_{2}$ concentrations of $<100 \mu \mathrm{m}$ applied selectively to neurites. Substantial neurite degeneration is observed with $250 \mu \mathrm{M} \mathrm{H}_{2} \mathrm{O}_{2}$ and nearly complete degeneration is exhibited by neurites administered $500 \mu \mathrm{M} \mathrm{H}_{2} \mathrm{O}_{2}$. $B$, Across-treatment-group comparisons demonstrate that blockade of sodium channels with TTX $(0.3 \mu \mathrm{m})$ does not provide protection from $350 \mu \mathrm{M} \mathrm{H} \mathrm{H}_{2} \mathrm{O}_{2}$-induced neurite degeneration at day 3 or day 6 (not significant, n.s.; $n=12$ compartments each for $\mathrm{H}_{2} \mathrm{O}_{2}$ and $\mathrm{H}_{2} \mathrm{O}_{2}+\mathrm{TTX}$ conditions, respectively). Treatment of neurites with $500 \mu \mathrm{M} \mathrm{H}_{2} \mathrm{O}_{2}$ induced greater degeneration than 350 $\mu \mathrm{M} \mathrm{H}_{2} \mathrm{O}_{2}$ and neurite degeneration was not protected by TTX treatment at day 3 or day 6 (not significant, n.s.; $n=6$ and 7 compartments each for $\mathrm{H}_{2} \mathrm{O}_{2}$ and $\mathrm{H}_{2} \mathrm{O}_{2}+$ TTX conditions, respectively). Neurite lengths are normalized to pretreatment lengths (pre) for each individual neurite compartment at days 3 and 6, respectively. Data are presented as mean \pm SEM.

\section{$\mathrm{H}_{2} \mathrm{O}_{2}$ induces neurite degeneration that is not attenuated by blockade of sodium channel activity}

To mimic increased ROS production, we administered the oxidant $\mathrm{H}_{2} \mathrm{O}_{2}$ to neurites in the peripheral compartments. To establish a concentration of $\mathrm{H}_{2} \mathrm{O}_{2}$ that induced significant neurite degeneration during the timeframe of our experiment $(6 \mathrm{~d})$, we performed preliminary studies that exposed neurites to $0,5,10$, 50, 100, 250, and $500 \mu \mathrm{M} \mathrm{H} \mathrm{H}_{2} \mathrm{O}_{2}$. As demonstrated in Figure $6 \mathrm{~A}$, concentrations of $\mathrm{H}_{2} \mathrm{O}_{2}$ within the range of $250-500 \mu \mathrm{M}$ were sufficient to cause substantial neurite degeneration at $3 \mathrm{~d}$ after treatment. From these observations, two different concentrations of $\mathrm{H}_{2} \mathrm{O}_{2}, 350$ and $500 \mu \mathrm{M}$, were selected to study $\mathrm{H}_{2} \mathrm{O}_{2}$-induced neurite degeneration. Comparison of neurites treated with 350 $\mu \mathrm{M} \mathrm{H}_{2} \mathrm{O}_{2}$ (Fig. $6 \mathrm{~B}$ ) with time-matched untreated control neurites (Fig. $2 F$ ) demonstrates that $350 \mu \mathrm{M} \mathrm{H}_{2} \mathrm{O}_{2}$ induced significant neurite degeneration at days 3 and $6\left(350 \mu \mathrm{M} \mathrm{H}_{2} \mathrm{O}_{2}\right.$ : day $3,58.1 \pm$ 5.3; day 6, $49.0 \pm 6.7$ vs control: day $3,119.5 \pm 13.6$; day 6 , $140.7 \pm 15.7$; Student's unpaired $t$ test, $p<0.05$ ), producing reductions in neurite lengths of $51 \%$ and $65 \%$ at days 3 and 6 , respectively. Similar comparison of neurites treated with $500 \mu \mathrm{M}$ $\mathrm{H}_{2} \mathrm{O}_{2}$ (Fig. $6 \mathrm{~B}$ ) with time-matched untreated control neurites (Fig. $2 F$ ) demonstrate that $500 \mu \mathrm{M} \mathrm{H}_{2} \mathrm{O}_{2}$ induced significant neurite degeneration at days 3 and $6\left(500 \mu \mathrm{M} \mathrm{H}_{2} \mathrm{O}_{2}\right.$ : day $3,40.2 \pm 2.5$; day $6,24.0 \pm 3.3$ vs control: day $3,119.5 \pm 13.6$; day $6,140.7 \pm$ 15.7; Student's unpaired $t$ test, $p<0.05$ ), producing reductions in neurite lengths of $\sim 66 \%$ and $\sim 83 \%$ at days 3 and 6 , respectively.

To determine whether the $\mathrm{H}_{2} \mathrm{O}_{2}$-induced neurite degeneration was attenuated by blockade of sodium channels, we coadministered TTX and $\mathrm{H}_{2} \mathrm{O}_{2}(350$ and $500 \mu \mathrm{M})$ to neurites. Time-matched comparisons demonstrate that neurites treated with $350 \mu \mathrm{M} \mathrm{H}_{2} \mathrm{O}_{2}+$ TTX (Fig. 6B) exhibited significant neurite degeneration at days 3 and 6 compared with TTX-treated controls $\left(350 \mu \mathrm{M} \mathrm{H}_{2} \mathrm{O}_{2}+\right.$ TTX: day 3, $55.0 \pm 6.6$; day $6,51.4 \pm 9.6$ vs TTX: day 3 , $117.9 \pm 10.5$; day $6,122.8 \pm 11.1$; Student's unpaired $t$ test, $p<0.05$; Fig. $2 F$ ), producing decreases in neurite lengths of $\sim 53 \%$ and $\sim 58 \%$ at days 3 and 6 , respectively. Similar time-matched comparisons demonstrate that $500 \mu \mathrm{M} \mathrm{H} \mathrm{H}_{2} \mathrm{O}_{2}$ induced significant neurite degeneration at days 3 and 6 compared with TTX-treated controls (500 $\mu \mathrm{M} \mathrm{H}_{2} \mathrm{O}_{2}+$ TTX: day 3, $45.7 \pm$ 3.9; day 6, $27.4 \pm 3.9$ vs TTX: day 3 , $117.9 \pm 10.5$; day $6,122.8 \pm 11.1$; Student's unpaired $t$ test, $p<0.05$; Fig. $2 F$ ), producing reductions in neurite lengths of $\sim 61 \%$ and $\sim 78 \%$ at days 3 and 6 , respectively. Across-treatment-group comparisons demonstrate that blockade of sodium channels with TTX did not provide significant protection from neurite degeneration induced by 350 or $500 \mu \mathrm{M}$ $\mathrm{H}_{2} \mathrm{O}_{2}$ at days 3 and 6 (Fig. 6B).

\section{Neurite degeneration induced by rotenone is autonomous from cell death}

Axonal degeneration has been suggested to be an autonomous process occurring through mechanisms distinct from those of cell death and some degenerative disorders have been suggested to affect axons selectively, with no direct damage or secondary axonal degenerative-induced damage of cell bodies (Coleman and Freeman, 2010; Courchesne et al., 2011). To determine whether neurite degeneration occurred independently of cell death, we used PI (applied to the compartment with cell bodies) as a marker of damaged cells. Three days after rotenone was administered selectively to neurites (at a time when substantial neurite degeneration had occurred), the percentage of PI-positive cells in the center compartments was not significantly different from those of controls $(4.1 \pm 1.4 \%$ compared with $4.8 \pm 1.3 \%$; Student's unpaired $t$ test, $p<0.05$; Fig. 7), indicating that application of rotenone to peripheral compartments induced degeneration of neurites without causing cell death. As expected, membrane disruption by the positive control (digitonin) displayed robust PI labeling of nuclei (Fig. 7).

\section{Delayed $\mathrm{Ca}^{2+}$ clearance after activation of rotenone-treated neurites}

Primary sensory neurons express voltage-gated calcium channels and membrane depolarization initiates rapid influx of $\mathrm{Ca}^{2+}$. Under normal conditions, $\mathrm{Ca}^{2+}$ that enters the cell during neuronal activation is quickly cleared from the cytoplasm through a battery of $\mathrm{Ca}^{2+}$-transporting mechanisms, most of which are ATP dependent (Benham et al., 1992; Werth et al., 1996; Gover et al., 2007). Proper $\mathrm{Ca}^{2+}$ regulation is crucial for neuronal survival and pathologically elevated cytosolic $\mathrm{Ca}^{2+}$ levels can trigger multiple destructive processes, including initiation of proteolytic activity resulting in cytoskeleton disruption and DNA and organelle damage (Orrenius et al., 1989). To examine activityinitiated $\mathrm{Ca}^{2+}$ transients in rotenone-treated, energy- 
A

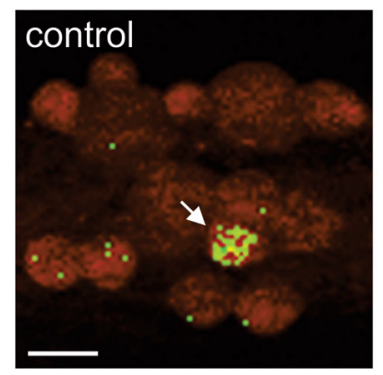

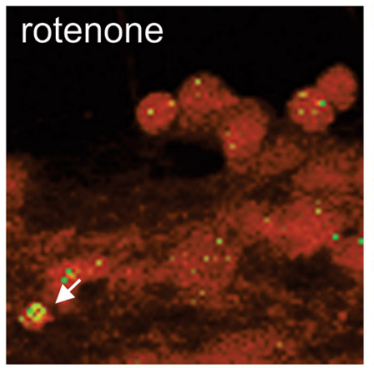

B

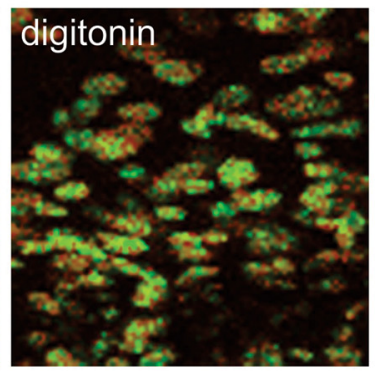

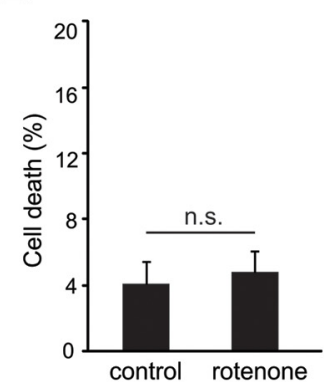

Figure 7. Rotenone treatment of neurites does not induce cell death. $\boldsymbol{A}$, Cell bodies of DRG neurons in middle compartment of control cultures exhibit limited PI labeling of nuclei (arrow). Three days after rotenone treatment targeted selectively to neurites in peripheral compartments of culture chambers, few cell bodies display PI labeling (arrow). Note: For comparison, cells treated with digitonin, a membrane-rupturing detergent, exhibited robust PI labeling of nuclei, with no intact, PI-negative neurons present. Scale bar, $25 \mu$ m. $\boldsymbol{B}, 0$ uantification of cell death indicates that $<5 \%$ of control and rotenone-treated neurons display PI labeling (n.S., not significant; $n=21$ fields of view each for control and rotenone conditions). Data are presented as mean \pm SEM.

deficient neurites, we assayed $\mathrm{Ca}^{2+}$ transients using Fura-2. Free $\mathrm{Ca}^{2+}$ levels were measured as the ratio of Fura- 2 emission intensities evoked with $340\left(F_{340}\right)$ and $380\left(F_{380}\right)$ nm excitations. Membrane depolarization in the neurites was induced by microperfusion with a high $\left[\mathrm{K}^{+}\right]$concentration solution $(140 \mathrm{mM}$ $\mathrm{KCl})$, causing a rapid inward $\mathrm{Ca}^{2+}$ transient and increase in cytosolic $\mathrm{Ca}^{2+}$ levels. Seconds later, the $\mathrm{Ca}^{2+}$ transient peak amplitude was reached and clearance of cytoplasmic $\mathrm{Ca}^{2+}$ initiated. In rotenonetreated neurites ( $1 \mu \mathrm{M}$ for $20 \mathrm{~h}$ ), the peak in $R_{340 / 380}$ was similar to that of control neurites $\left(R_{\text {Peak }}=4.6\right.$ for the control and $R_{\text {Peak }}=4.5$ for the rotenone group; Fig. $8 A$ ). However, there was a significant reduction in decay rate of the $\mathrm{Ca}^{2+}$ transient after activation in these neurites compared with control (Fig. 8A). Quantification of the $\mathrm{Ca}^{2+}$ clearance rate, as measured by AUC, demonstrated a delay in clearance in rotenone-treated neurites (123 \pm 27 a.u.) compared with control $(65.0 \pm 9.5$ a.u.; $p<0.05$; Fig. $8 B$ ). Neurites treated with TTX in combination with rotenone exhibited a reversal of the delayed $\mathrm{Ca}^{2+}$ clearance (Fig. 8C), exhibiting AUC values of $89.3 \pm 11.4$ compared with rotenone-treated neurites (133 \pm 15.2; $p<0.05$; Fig. 8D).

\section{Discussion}

Axonal degeneration has been linked to the pathophysiology of multiple neurological conditions, including CNS disorders such as multiple sclerosis, Alzheimer's disease, and Parkinson's disease (Waxman, 2006; Zambonin et al., 2011; Campbell et al., 2012; Lingor et al., 2012) and PNS disorders such as Charcot-Marie-Tooth disease and small fiber neuropathy (Lacomis, 2002; Pareyson and Marchesi, 2009). Although etiologically and regionally distinct, accumulating evidence suggests that these disorders share common mechanisms that can initiate injurious cascades leading to axonal
A

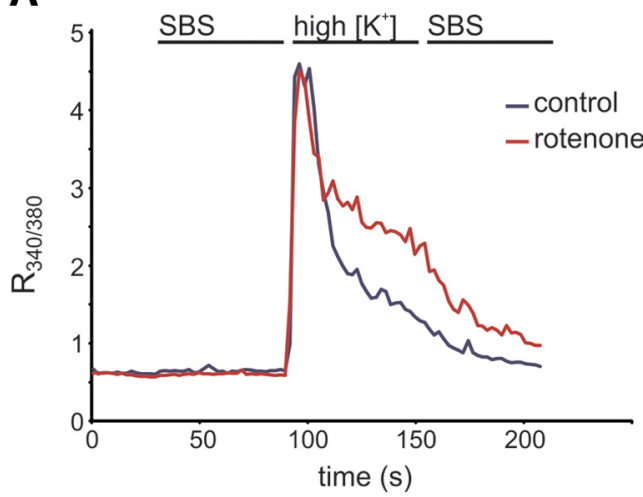

B

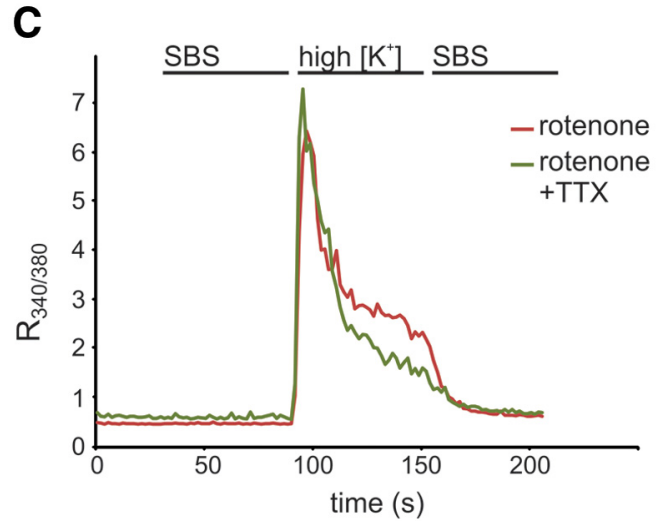

Figure 8. Sodium channel blockade restores rotenone-induced inhibition of neurite $\left[\mathrm{Ca}^{2+}\right]_{\mathrm{i}}$ recovery to depolarization. $\boldsymbol{A}$, Neurites in peripheral compartments of Campenot chambers treated with rotenone for $20 \mathrm{~h}$ exhibit reduced capacity to clear increased levels of intracellular $\mathrm{Ca}^{2+}$ after high $\left[\mathrm{K}^{+}\right]$-induced membrane depolarization compared with control neurites. The initial (10-15 s) recovery from high $\left[\mathrm{Ca}^{2+}\right]_{\mathrm{i}}$ is similar between control and rotenone-treated neurites, but $\mathrm{Ca}^{2+}$ clearance is substantially slower after this initial period in rotenone-treated versus control neurites. Curves represent means of $n=23$ control and $n=23$ rotenone-treated neurites. $\boldsymbol{B}$, Quantification of $\left[\mathrm{Ca}^{2+}\right]_{\mathrm{i}}$ recovery after depolarization demonstrates that the AUC for rotenone-treated neurites is $\sim 2$-fold that of control neurites ( ${ }^{*} p<0.05 ; n=23$ control and 23 rotenone-treated neurites). $\boldsymbol{C}$, Neurites treated with TTX and rotenone exhibit increased capacity to clear intracellular $\mathrm{Ca}^{2+}$ compared with neurites treated with rotenone only. The initial (10-15s) recovery from high $\left[\mathrm{Ca}^{2+}\right]_{i}$ is similar between rotenone and rotenone with $\mathrm{TTX}_{1}$, but $\mathrm{Ca}^{2+}$ sequestering is enhanced after this initial period with TTX treatment. Curves represent means of $n=13$ rotenone and $n=17$ rotenone + TTX-treated neurites. $\boldsymbol{D}$, Quantification of $\left[\mathrm{Ca}^{2+}\right]_{\mathrm{i}}$ recovery after depolarization demonstrates that the AUC for neurites with TTX treatment is approximately one-half of that for rotenone only $\left({ }^{*} p<0.05 ; n=13\right.$ rotenone and $n=17$ rotenone + TTX-treated neurites). Data are presented as mean \pm SEM.

degeneration. In particular, impaired mitochondrial function and/or disrupted axonal transport have been identified as contributors to axonal degenerative pathways (Zuchner et al., 2004; Lehmann et al., 2011; Court and Coleman, 2012; Millecamps and Julien, 
2013). Here, we used a short-term tissue culture system that isolated cell bodies from neurites to demonstrate that the metabolic inhibitor rotenone, when selectively applied to neurites of DRG neurons, induces degeneration of these neuronal processes and that blockade of sodium channels and reverse NCX activity provides partial protection from disruption of the neurites. These observations implicate a contribution of sodium channels and NCX in pathways leading to acute degeneration of axons.

Early support for a contribution of sodium channel activity in axonal degeneration pathways was provided by Stys et al. (1992), who showed that anoxia-induced axonal damage in an in vitro optic nerve preparation was linked to persistent sodium influx through voltage-gated sodium channels. In this and subsequent studies, injury to PNS and CNS axons was associated with a reduced $\mathrm{Na}^{+} / \mathrm{K}^{+}$ATPase capacity, with $\mathrm{Na}^{+}$influx exceeding the capability of $\mathrm{Na}^{+}$ export. Subsequent increases in intraaxonal $\mathrm{Na}^{+}$was posited to cause reversal of NCX, such that it operated in $\mathrm{Ca}^{2+}$-importing mode, resulting in intraaxonal $\mathrm{Ca}^{2+}$ overload and the initiation of $\mathrm{Ca}^{2+}$-driven injurious cascades (Stys et al., 1992; Lehning et al., 1996; Li et al., 2000). In support of this proposal, multiple studies have demonstrated a protective effect of sodium channel blockers on axons in experimental in vivo models of PNS and CNS injuries (Bechtold et al., 2005; Kaptanoglu et al., 2005; Morsali et al., 2013).

A link between sodium channels and axonal injury was also provided by recent studies that identified variants of sodium channels $\mathrm{Na}_{\mathrm{V}} 1.7$ and $\mathrm{Na}_{\mathrm{V}} 1.8$ in patients manifesting idiopathic SFN (Faber et al., 2012a; Faber et al., 2012b). When transfected into DRG neurons in vitro, these channel variants demonstrated gain-of-function properties, leading to reduced threshold, increased frequency of evoked firing, and abnormal spontaneous firing (Faber et al., 2012a; Faber et al., 2012b). In a functional assay examining sensory neurites in vitro, expression of the SFNassociated $\mathrm{Na}_{\mathrm{V}} 1.7$ variant $\mathrm{I} 228 \mathrm{M}$ was associated with impaired neurite integrity, which was rescued by the activity-dependent sodium channel blocker carbamazepine, suggesting a link between aberrant sodium channel activity and axonal damage in peripheral sensory neurons (Persson et al., 2013).

In the present study, we determined the contribution of sodium channels to neurite degeneration of peripheral neurons in two separate in vitro models of axonal degeneration: impaired mitochondrial function and microtubule disruption. Although peripheral neuropathies can develop over decades (and initially affect longer axons that can extend for nearly a meter), we reasoned that some mechanisms contributing to axonal injury can be studied in short-term tissue culture models such as the one used here. Most previous in vitro studies that addressed mechanisms of axonal degeneration of peripheral sensory neurons examined neurites after application of experimental reagents to both cell bodies and processes using explants or dispersed DRG cultures (Wang et al., 2000; Press and Milbrandt, 2008). However, in peripheral neuropathies, the distal nerve endings initially affected are often located $>1 \mathrm{~m}$ away from the soma and encounter a different microenvironment in the periphery compared with cell bodies close to the CNS. Moreover, there is evidence suggesting that mitochondria in soma and axons exhibit distinct properties, such as differential susceptibility to environmental stressors and toxins (Court and Coleman, 2012). We cultured DRG neurons in compartmental chambers, separating cell bodies and neurites, thus allowing selective treatment of neurites without affecting cell bodies directly (Campenot et al., 2009).

Compromised mitochondrial function in neurites was induced by application of rotenone, an agent that disrupts cellular respiration by inhibiting complex I of the mitochondrial electron transport chain (Arnold et al., 2011; Heitz et al., 2012; Huang et al., 2013). Rotenone was shown previously to cause axonal degeneration when administered to cell bodies and neurites in DRG cultures in vitro (Press and Milbrandt, 2008). We found that rotenone applied selectively to neurites induced degeneration of these processes, which was attenuated by blockade of sodium channels with TTX, and of reverse sodium-calcium exchange with KB-R7943, suggesting a contribution of sodium influx and reversed action of NCX in the degenerative pathway. Importantly, TTX and KB-R7943 did not completely inhibit rotenoneinduced neurite degeneration in our in vitro model, but rather provided a partial protective effect on the neurites. These observations thus indicate that sodium channels and reverse NCX activity participate in the pathological processes resulting in axonal degeneration under conditions of impaired mitochondrial function, along with additional injurious mechanisms that require further study.

The downstream molecular pathways by which mitochondrial dysfunction causes axonal degeneration have yet to be fully elucidated; however, both impaired ATP production and oxidative stress (e.g., production of ROS) have been suggested as key components in the degenerative process (Court and Coleman, 2012; Federico et al., 2012; Park et al., 2013). To examine these constituents of the degenerative pathway in rotenone-treated neurites, we first established that rotenone targeted selectively to neurites reduced ATP and increased ROS levels in the neurites. In neurons, a major portion of available ATP is used by the $\mathrm{Na}^{+}$/ $\mathrm{K}^{+}$-ATPase in the transport of $\mathrm{Na}^{+}$and $\mathrm{K}^{+}$ions against their concentration gradients to maintain ionic gradients across the cell membrane. $\mathrm{Na}^{+} / \mathrm{K}^{+}$-ATPase activity represents $\sim 50 \%$ of all energy consumption in the brain (Ames, 2000). In energydeprived axons, as under conditions of impaired cellular respiration and reduced mitochondrial ATP production, increased $\mathrm{Na}^{+}$-influx as a result of reduced capacity for $\mathrm{Na}^{+}$export by $\mathrm{Na}^{+} / \mathrm{K}^{+}$-ATPase and subsequent membrane depolarization would thus be predicted to occur. Thin, unmyelinated axons would be anticipated to be particularly vulnerable to fluctuations in intraaxonal ATP levels due to their high surface-to-volume ratio, high input resistance, and short diffusional and electrotonic length constant, requiring significant $\mathrm{Na}^{+} / \mathrm{K}^{+}$-ATPase activity to maintain ionic gradients (Waxman et al., 1989; Donnelly, 2008). It is interesting that unmyelinated, small-diameter peripheral axons in human nerves appear to be especially sensitive to hypoxia (Malik et al., 1990).

Impaired $\mathrm{Na}^{+} / \mathrm{K}^{+}$-ATPase activity in ATP-deficient neurites was mimicked by pharmacological blockade of $\mathrm{Na}^{+} / \mathrm{K}^{+}$-ATPase with ouabain (Agrawal and Fehlings, 1996). Ouabain induced neurite degeneration that was ameliorated by sodium channel blockade. In contrast, the oxidant $\mathrm{H}_{2} \mathrm{O}_{2}$ caused neurite degeneration that was not protected by blockade of sodium channels. These observations are consistent with a contribution of sodium channels in degradative pathways induced by low intraneuritic ATP levels, but not increased levels of ROS. These findings are in contrast to those of Press and Milbrandt (2008), who found that blockade of sodium channels was not protective after oxidant stress applied to cell bodies and neurites of dispersed DRG cultures.

In addition to impaired mitochondrial function, we examined whether sodium channels and reverse NCX activity can contribute to neurite degeneration induced by microtubule disruption. We used the chemotherapeutic agent vincristine, which disrupts microtubule polymerization and elicits neurite degeneration in 
cultured DRG neurons (Wang et al., 2000). Similar to rotenone, vincristine induced degeneration when administered to neurites, but blockage of sodium channels or reverse NCX activity did not protect neurites, indicating that alternative pathways contribute to neurite degeneration in these two models of axonal degeneration.

Sustained increased intracellular $\mathrm{Ca}^{2+}$ levels are associated with the onset of degradative cascades leading to axonal degeneration (Stirling and Stys, 2010; Wang et al., 2012). To determine whether rotenone-treated neurites exhibit reduced capacity to restore $\mathrm{Ca}^{2+}$ levels after neuronal activity, ratiometric Fura-2based $\mathrm{Ca}^{2+}$ imaging was used to examine intraneuritic $\mathrm{Ca}^{2+}$ transients. Neuritic membrane depolarization caused a rapid influx of $\mathrm{Ca}^{2+}$ into neurites, followed by an initial fast and then slower sustained recovery of $\left[\mathrm{Ca}^{2+}\right]_{\mathrm{i}}$ levels. In comparison with controls, rotenone-treated neurites exhibited a delayed recovery of $\left[\mathrm{Ca}^{2+}\right]_{\mathrm{i}}$ levels, possibly reflecting a reduction in available cytosolic ATP and impaired function of ATP-driven $\mathrm{Ca}^{2+}$ exporting pumps. The delay in $\mathrm{Ca}^{2+}$ clearance occurs in the later phase of recovery, whereas the initial decrease in $\mathrm{Ca}^{2+}$ transient seems unaffected in rotenone-treated neurites. Consistent with this observation, NCX appears to be a major contributor to initial, ATP-independent $\mathrm{Ca}^{2+}$ export after $\mathrm{Ca}^{2+}$ load; NCX has a low affinity for $\mathrm{Ca}^{2+}$, but is known to operate as a high-capacity $\mathrm{Ca}^{2+}$ exporter at intracellular $\mathrm{Ca}^{2+}$ levels exceeding the physiological range (DiPolo and Beaugé, 1979; Carafoli et al., 2001). TTX application to rotenone-treated neurites enhanced $\mathrm{Ca}^{2+}$ clearance after depolarization compared with neurites without TTX treatment, correlating with the protective effect of TTX on degenerating rotenone-treated neurites.

Our results demonstrate that the activity of sodium channels and NCX can contribute to axonal injury of peripheral axons resulting from mitochondrial dysfunction and impaired activity of $\mathrm{Na}^{+} / \mathrm{K}^{+}$-ATPase. Fern et al. (1993) demonstrated that the clinically used sodium channel blockers phenytoin and carbamazepine can protect optic nerve axons from anoxic injury in vitro. The present results suggest that blockade of sodium channels or reverse NCX, either nonselective or targeting specific isoforms, merit further study as an approach that might provide a protective effect in CNS and PNS disorders that are associated with axonal degeneration.

\section{References}

Agrawal SK, Fehlings MG (1996) Mechanisms of secondary injury to spinal cord axons in vitro: role of $\mathrm{Na}+, \mathrm{Na}(+)-\mathrm{K}(+)$-ATPase, the $\mathrm{Na}(+)-\mathrm{H}+$ exchanger, and the $\mathrm{Na}(+)-\mathrm{Ca}^{2+}$ exchanger. J Neurosci 16:545-552. Medline

Ames A 3rd (2000) CNS energy metabolism as related to function. Brain Res Brain Res Rev 34:42-68. CrossRef Medline

Arnold B, Cassady SJ, VanLaar VS, Berman SB (2011) Integrating multiple aspects of mitochondrial dynamics in neurons: age-related differences and dynamic changes in a chronic rotenone model. Neurobiol Dis 41: 189-200. CrossRef Medline

Baggaley EM, Elliott AC, Bruce JI (2008) Oxidant-induced inhibition of the plasma membrane $\mathrm{Ca}^{2+}$-ATPase in pancreatic acinar cells: role of the mitochondria. Am J Physiol Cell Physiol 295:C1247-1260. CrossRef Medline

Bechtold DA, Yue X, Evans RM, Davies M, Gregson NA, Smith KJ (2005) Axonal protection in experimental autoimmune neuritis by the sodium channel blocking agent flecainide. Brain 128:18-28. CrossRef Medline

Bednarik J, Vlckova-Moravcova E, Bursova S, Belobradkova J, Dusek L, Sommer C (2009) Etiology of small-fiber neuropathy. J Peripher Nerv Syst 14:177-183. CrossRef Medline

Benham CD, Evans ML, McBain CJ (1992) $\mathrm{Ca}^{2+}$ efflux mechanisms following depolarization evoked calcium transients in cultured rat sensory neurones. J Physiol 455:567-583. Medline
Boyette-Davis JA, Cata JP, Driver LC, Novy DM, Bruel BM, Mooring DL, Wendelschafer-Crabb G, Kennedy WR, Dougherty PM (2013) Persistent chemoneuropathy in patients receiving the plant alkaloids paclitaxel and vincristine. Cancer Chemother Pharmacol 71:619-626. CrossRef Medline

Campbell GR, Ohno N, Turnbull DM, Mahad DJ (2012) Mitochondrial changes within axons in multiple sclerosis: an update. Curr Opin Neurol 25:221-230. CrossRef Medline

Campenot RB (1977) Local control of neurite development by nerve growth factor. Proc Natl Acad Sci U S A 74:4516-4519. CrossRef Medline

Campenot RB, Lund K, Mok SA (2009) Production of compartmented cultures of rat sympathetic neurons. Nat Protoc 4:1869-1887. CrossRef Medline

Carafoli E, Santella L, Branca D, Brini M (2001) Generation, control, and processing of cellular calcium signals. Crit Rev Biochem Mol Biol 36:107260. CrossRef Medline

Catterall WA, Goldin AL, Waxman SG (2005) International Union of Pharmacology. XLVII. Nomenclature and structure-function relationships of voltage-gated sodium channels. Pharmacol Rev 57:397-409. CrossRef Medline

Chen H, Chan DC (2009) Mitochondrial dynamics-fusion, fission, movement, and mitophagy-in neurodegenerative diseases. Hum Mol Genet 18:R169-176. CrossRef Medline

Coleman MP, Freeman MR (2010) Wallerian degeneration, wld(s), and nmnat. Annu Rev Neurosci 33:245-267. CrossRef Medline

Courchesne SL, Karch C, Pazyra-Murphy MF, Segal RA (2011) Sensory neuropathy attributable to loss of Bcl-w. J Neurosci 31:1624-1634. CrossRef Medline

Court FA, Coleman MP (2012) Mitochondria as a central sensor for axonal degenerative stimuli. Trends Neurosci 35:364-372. CrossRef Medline

Cummins TR, Howe JR, Waxman SG (1998) Slow closed-state inactivation: a novel mechanism underlying ramp currents in cells expressing the hNE/ PN1 sodium channel. J Neurosci 18:9607-9619. Medline

Delettre C, Lenaers G, Griffoin JM, Gigarel N, Lorenzo C, Belenguer P, Pelloquin L, Grosgeorge J, Turc-Carel C, Perret E, Astarie-Dequeker C, Lasquellec L, Arnaud B, Ducommun B, Kaplan J, Hamel CP (2000) Nuclear gene OPA1, encoding a mitochondrial dynamin-related protein, is mutated in dominant optic atrophy. Nat Genet 26:207-210. CrossRef Medline

Dib-Hajj SD, Choi JS, Macala LJ, Tyrrell L, Black JA, Cummins TR, Waxman SG (2009) Transfection of rat or mouse neurons by biolistics or electroporation. Nat Protoc 4:1118-1126. CrossRef Medline

DiPolo R, Beaugé L (1979) Physiological role of ATP-driven calcium pump in squid axon. Nature 278:271-273. CrossRef Medline

Donnelly DF (2008) Spontaneous action potential generation due to persistent sodium channel currents in simulated carotid body afferent fibers. J Appl Physiol 104:1394-1401. CrossRef Medline

Dutta R, McDonough J, Yin X, Peterson J, Chang A, Torres T, Gudz T, Macklin WB, Lewis DA, Fox RJ, Rudick R, Mirnics K, Trapp BD (2006) Mitochondrial dysfunction as a cause of axonal degeneration in multiple sclerosis patients. Ann Neurol 59:478-489. CrossRef Medline

England JD, Asbury AK (2004) Peripheral neuropathy. Lancet 363:21512161. CrossRef Medline

Faber CG, Hoeijmakers JG, Ahn HS, Cheng X, Han C, Choi JS, Estacion M, Lauria G, Vanhoutte EK, Gerrits MM, Dib-Hajj S, Drenth JP, Waxman SG, Merkies IS (2012a) Gain of function Nanu1.7 mutations in idiopathic small fiber neuropathy. Ann Neurol 71:26-39. CrossRef Medline

Faber CG, Lauria G, Merkies IS, Cheng X, Han C, Ahn HS, Persson AK, Hoeijmakers JG, Gerrits MM, Pierro T, Lombardi R, Kapetis D, Dib-Hajj SD, Waxman SG (2012b) Gain-of-function Nav1.8 mutations in painful neuropathy. Proc Natl Acad Sci U S A 109:19444-19449. CrossRef Medline

Federico A, Cardaioli E, Da Pozzo P, Formichi P, Gallus GN, Radi E (2012) Mitochondria, oxidative stress and neurodegeneration. J Neurol Sci 322: 254-262. CrossRef Medline

Fern R, Ransom BR, Stys PK, Waxman SG (1993) Pharmacological protection of CNS white matter during anoxia: actions of phenytoin, carbamazepine and diazepam. J Pharmacol Exp Ther 266:1549-1555. Medline

Gover TD, Moreira TH, Kao JP, Weinreich D (2007) Calcium regulation in individual peripheral sensory nerve terminals of the rat. J Physiol 578: 481-490. CrossRef Medline

Hains BC, Waxman SG (2005) Neuroprotection by sodium channel block- 
ade with phenytoin in an experimental model of glaucoma. Invest Ophthalmol Vis Sci 46:4164-4169. CrossRef Medline

Hains BC, Saab CY, Lo AC, Waxman SG (2004) Sodium channel blockade with phenytoin protects spinal cord axons, enhances axonal conduction, and improves functional motor recovery after contusion SCI. Exp Neurol 188:365-377. CrossRef Medline

Heitz FD, Erb M, Anklin C, Robay D, Pernet V, Gueven N (2012) Idebenone protects against retinal damage and loss of vision in a mouse model of Leber's hereditary optic neuropathy. PLoS One 7:e45182. CrossRef Medline

Huang Q, Wang H, Perry SW, Figueiredo-Pereira ME (2013) Negative regulation of $26 \mathrm{~S}$ proteasome stability via calpain-mediated cleavage of Rpn10 subunit upon mitochondrial dysfunction in neurons. J Biol Chem 288:12161-12174. CrossRef Medline

Kaptanoglu E, Solaroglu I, Surucu HS, Akbiyik F, Beskonakli E (2005) Blockade of sodium channels by phenytoin protects ultrastructure and attenuates lipid peroxidation in experimental spinal cord injury. Acta Neurochir (Wien) 147:405-412; discussion 412. Medline

Kiryu-Seo S, Ohno N, Kidd GJ, Komuro H, Trapp BD (2010) Demyelination increases axonal stationary mitochondrial size and the speed of axonal mitochondrial transport. J Neurosci 30:6658-6666. CrossRef Medline

Lacomis D (2002) Small-fiber neuropathy. Muscle Nerve 26:173-188. CrossRef Medline

Lehmann HC, Chen W, Borzan J, Mankowski JL, Höke A (2011) Mitochondrial dysfunction in distal axons contributes to human immunodeficiency virus sensory neuropathy. Ann Neurol 69:100-110. CrossRef Medline

Lehning EJ, Doshi R, Isaksson N, Stys PK, LoPachin RM Jr (1996) Mechanisms of injury-induced calcium entry into peripheral nerve myelinated axons: role of reverse sodium-calcium exchange. J Neurochem 66:493500. CrossRef Medline

Leinster VH, Robson LG, Shortland PJ (2010) Differential effects of riluzole on subpopulations of adult rat dorsal root ganglion neurons in vitro. Neuroscience 166:942-951. CrossRef Medline

Leyssens A, Nowicky AV, Patterson L, Crompton M, Duchen MR (1996) The relationship between mitochondrial state, ATP hydrolysis, $\left[\mathrm{Mg}^{2+}\right] \mathrm{i}$ and $\left[\mathrm{Ca}^{2+}\right] \mathrm{i}$ studied in isolated rat cardiomyocytes. J Physiol 496:111128. Medline

Li S, Jiang Q, Stys PK (2000) Important role of reverse $\mathrm{Na}(+)-\mathrm{Ca}\left({ }^{2+}\right)$ exchange in spinal cord white matter injury at physiological temperature. J Neurophysiol 84:1116-1119. Medline

Lingor P, Koch JC, Tönges L, Bähr M (2012) Axonal degeneration as a therapeutic target in the CNS. Cell Tissue Res 349:289-311. CrossRef Medline

Malik RA, Masson EA, Sharma AK, Lye RH, Ah-See AK, Compton AM, Tomlinson DR, Hanley SP, Boulton AJ (1990) Hypoxic neuropathy: relevance to human diabetic neuropathy. Diabetologia 33:311-318. CrossRef Medline

Millecamps S, Julien JP (2013) Axonal transport deficits and neurodegenerative diseases. Nat Rev Neurosci 14:161-176. CrossRef Medline

Morsali D, Bechtold D, Lee W, Chauhdry S, Palchaudhuri U, Hassoon P, Snell DM, Malpass K, Piers T, Pocock J, Roach A, Smith KJ (2013) Safinamide and flecainide protect axons and reduce microglial activation in models of multiple sclerosis. Brain 136:1067-1082. CrossRef Medline

Orrenius S, McConkey DJ, Bellomo G, Nicotera P (1989) Role of $\mathrm{Ca}^{2+}$ in toxic cell killing. Trends Pharmacol Sci 10:281-285. CrossRef Medline

Pardo CA, McArthur JC, Griffin JW (2001) HIV neuropathy: insights in the pathology of HIV peripheral nerve disease. J Peripher Nerv Syst 6:21-27. CrossRef Medline

Pareyson D, Marchesi C (2009) Diagnosis, natural history, and management of Charcot-Marie-Tooth disease. Lancet Neurol 8:654-667. CrossRef Medline
Park JY, Jang SY, Shin YK, Koh H, Suh DJ, Shinji T, Araki T, Park HT (2013) Mitochondrial swelling and microtubule depolymerization are associated with energy depletion in axon degeneration. Neuroscience 238:258-269. CrossRef Medline

Pavlakis PP, Alexopoulos H, Kosmidis ML, Mamali I, Moutsopoulos HM, Tzioufas AG, Dalakas MC (2012) Peripheral neuropathies in Sjogren's syndrome: a critical update on clinical features and pathogenetic mechanisms. J Autoimmun 39:27-33. CrossRef Medline

Persson AK, Black JA, Gasser A, Cheng X, Fischer TZ, Waxman SG (2010) Sodium-calcium exchanger and multiple sodium channel isoforms in intra-epidermal nerve terminals. Mol Pain 6:84. CrossRef Medline

Persson AK, Liu S, Faber CG, Merkies IS, Black JA, Waxman SG (2013) Neuropathy-associated $\mathrm{Na}(\mathrm{V}) 1.7$ variant I228M impairs integrity of dorsal root ganglion neuron axons. Ann Neurol 73:140-145. CrossRef Medline

Press C, Milbrandt J (2008) Nmnat delays axonal degeneration caused by mitochondrial and oxidative stress. J Neurosci 28:4861-4871. CrossRef Medline

Sheng ZH, Cai Q (2012) Mitochondrial transport in neurons: impact on synaptic homeostasis and neurodegeneration. Nat Rev Neurosci 13:7793. CrossRef Medline

Shields SD, Ahn HS, Yang Y, Han C, Seal RP, Wood JN, Waxman SG, DibHajj SD (2012) $\mathrm{Na}(\mathrm{v}) 1.8$ expression is not restricted to nociceptors in mouse peripheral nervous system. Pain 153:2017-2030. CrossRef Medline

Stirling DP, Stys PK (2010) Mechanisms of axonal injury: internodal nanocomplexes and calcium deregulation. Trends Mol Med 16:160-170. CrossRef Medline

Stys PK, Waxman SG, Ransom BR (1992) Ionic mechanisms of anoxic injury in mammalian CNS white matter: role of $\mathrm{Na}+$ channels and $\mathrm{Na}(+)$ $\mathrm{Ca}^{2+}$ exchanger. J Neurosci 12:430-439. Medline

Tavee J, Zhou L (2009) Small fiber neuropathy: a burning problem. Cleve Clin J Med 76:297-305. CrossRef Medline

Wang JT, Medress ZA, Barres BA (2012) Axon degeneration: molecular mechanisms of a self-destruction pathway. J Cell Biol 196:7-18. CrossRef Medline

Wang MS, Wu Y, Culver DG, Glass JD (2000) Pathogenesis of axonal degeneration: parallels between Wallerian degeneration and vincristine neuropathy. J Neuropathol Exp Neurol 59:599-606. Medline

Watanabe Y, Koide Y, Kimura J (2006) Topics on the $\mathrm{Na}+/ \mathrm{Ca}^{2+}$ exchanger: pharmacological characterization of $\mathrm{Na}+/ \mathrm{Ca}^{2+}$ exchanger inhibitors. J Pharmacol Sci 102:7-16. CrossRef Medline

Waxman SG (2006) Axonal conduction and injury in multiple sclerosis: the role of sodium channels. Nat Rev Neurosci 7:932-941. CrossRef Medline

Waxman SG, Black JA, Kocsis JD, Ritchie JM (1989) Low density of sodium channels supports action potential conduction in axons of neonatal rat optic nerve. Proc Natl Acad Sci U S A 86:1406-1410. CrossRef Medline

Werth JL, Usachev YM, Thayer SA (1996) Modulation of calcium efflux from cultured rat dorsal root ganglion neurons. J Neurosci 16:10081015. Medline

Zambonin JL, Zhao C, Ohno N, Cambell GR, Engelham S, Ziabreva I, Schwartz N, Lee SE, Frischer JM, Turnbull DM, Trapp BD, Lassmann H, Franklin RJ, Mahad DJ (2011) Increased mitochondrial content in remyelinated axons: implications for multiple sclerosis. Brain 13:19011913. CrossRef Medline

Züchner S, Mersiyanova IV, Muglia M, Bissar-Tadmouri N, Rochelle J, Dadali EL, Zappia M, Nelis E, Patitucci A, Senderek J, Parman Y, Evgrafov O, Jonghe PD, Takahashi Y, Tsuji S, Pericak-Vance MA, Quattrone A, Battaloglu E, Polyakov AV, Timmerman V, et al. (2004) Mutations in the mitochondrial GTPase mitofusin 2 cause Charcot-Marie-Tooth neuropathy type 2A. Nat Genet 36:449-451. CrossRef Medline 